\title{
The Adverse Effect of Information on Governance and Leverage
}

\author{
Christian Laux, Gyöngyi Lóránth, and Alan D. Morrison *
}

June 2016

\begin{abstract}
We study the effect that internal information systems have upon a firm's leverage and corporate governance choices. Information systems lower governance costs by facilitating more targeted interventions. But they also generate asymmetric information between firms and their investors. As a result, firms may attempt to signal their superior quality by assuming more leverage. In some circumstances, this can reduce governance incentives and result in inferior outcomes. Investors anticipate this effect, and it renders information systems inefficient.
\end{abstract}

*We thank Christian Hofmann, Julian Kolm, Clemens Otto, and seminar participants at Johannes Gutenberg University Mainz, University of Graz, University of Mannheim, WU (Vienna University of Economics and Business), the European Finance Association meeting in Lugano, the SAFE Exploratory Workshop on Transparency at Goethe University Frankfurt, NHH (Bergen), and the accounting working group of the German Economic Association for valuable comments. The paper was significantly improved by the comments of two anonymous referees and the Associate Editor.

Correspondence address: Laux: WU (Vienna University of Economics and Business), Christian.Laux@wu.ac.at; Lóránth: University of Vienna, gyoengyi.loranth@univie.ac.at; Morrison: Saïd Business School, University of Oxford, alan.morrison@sbs.ox.ac.uk 
THE ADVERSE EFFECT OF INFORMATION ON GOVERNANCE AND LEVERAGE

\section{Introduction}

Since the start of this century, a series of high profile governance failures have placed the quality of internal reporting systems in the regulatory spotlight. For example, accounting scandals at Enron and Worldcom, amongst others, led to the 2002 passage of the Sarbanes-Oxley Act: Section 404 of the Act requires firms to attest to the effectiveness of their internal control systems.

Accurate internal reporting is an essential element of a firm's internal control systems. A wellgoverned firm should use information about its activities to identify possible managerial malpractice, and then to intervene where necessary to ensure good practice. But even now, we continue to see governance problems that can be attributed either to poor information, or to a failure to respond to the information generated by internal reporting systems. For example, the French Bank Société Générale incurred losses of $€ 4.9$ bn in 2008 after the Paris-based trader Jérôme Kerviel violated internal risk limits and manipulated the bank's internal information systems. ${ }^{1}$ More recently, the senior management of financial institutions appears to have been largely ignorant of severe market abuse in the LIBOR money market fixings. ${ }^{2}$

This paper presents an analysis of internal information systems and the way that firms respond to their output. At the heart of our model is the observation that it is difficult to stipulate contractually or in regulations how the information generated by information systems is used. In practice, much of the output from a firm's internal information systems is very hard to communicate to outside stakeholders, because the reporting system could rely upon soft information or context-specific reports that would be very hard for outsiders to interpret. Hence, while it is often clear to external stakeholders that a firm has implemented an information system, it may be impossible for those stakeholders to verify the information generated by the system, or to check that it has been acted upon.

Because it is hard for outsiders to interpret an internal information system, it has two effects: While it reduces information asymmetries within the firm, it creates a new adverse selection problem between the firm's senior managers and the firm's investors. In our model, firms attempt to signal the output of their reporting system to outside investors. We show that it is optimal to use high

\footnotetext{
${ }^{1}$ See "Kerviel found guilty in SocGen scandal," Scheherazade Daneshkhu, Financial Times Oct 5, 2010. https: //next.ft.com/content/bd166528-d05b-11df-afe1-00144feabdc0.

${ }^{2}$ For example, Bob Diamond, the former Barclays chief executive, stated explicitly that he was unaware of market practices in the LIBOR market: see http://www.nytimes.com/2013/05/05/magazine/robert-diamondsnext-life.html.
} 
THE ADVERSE EFFECT OF INFORMATION ON GOVERNANCE AND LEVERAGE

leverage when the information from the information system is favorable. As a result, some firms with an information system increase their debt levels so as to send a positive signal to their investors. The consequence of this leverage is that incentives to good corporate governance are undermined, so that the information system might not achieve what it is intended to.

Our analysis generates a fresh insight into policy debates concerning internal reporting systems and their use in internal control. Several authors have argued that forcing firms to implement reporting systems and to codify their use in internal controls may generate costs so high as to reduce firm value (e.g., Romano (2005)). We analyze the direct costs of such legislation, but we also identify an additional potential problem, arising when information systems shift asymmetric information problems from within the firm to across its boundaries, so causing new adverse selection problems between investors and corporate insiders.

We consider a firm run by a headquarters that aims to maximize the value of the firm's equity. The firm's managers have incentives that are imperfectly aligned with those of the headquarters: if they see an opportunity to extract personal benefits from a project at the expense of the shareholders then they take it. We refer to this behavior as shirking and, for much of our analysis, we leave its precise nature unspecified. For example, shirking could constitute a mis-direction of effort that generates managerial private benefits, as in Holmström and Tirole (1997). A specific type of shirking occurs when managers find ways to assume excessive risks to increase or protect their bonuses as, for example, in the case of Société Générale. The danger that shirking occurs is an important form of operational risk.

The headquarters can intervene to improve the governance of specific projects, and so to prevent managerial shirking. Once again, most of our model admits a number of interpretations of governance interventions. For example, they could involve the payment of bonuses to managers who achieve shareholder objectives, or they could be achieved through extra investment in making information systems harder to manipulate to prevent losses of the type sustained by Société Générale. In every case, however, governance interventions improve the value of projects that are subject to managerial shirking only at a cost.

Because they are concerned with hard-to-monitor phenomena, governance interventions cannot be observed by outside stakeholders; interventions do not require verifiable additional investment, and they often require actions by the corporate headquarters or its managers that are difficult for outsiders to observe. Moreover, some projects do not require any governance intervention at all. 
THE ADVERSE EFFECT OF INFORMATION ON GOVERNANCE AND LEVERAGE

Because governance interventions are unobservable, the headquarters cannot commit ex ante to an intervention policy. Governance interventions will therefore occur only if they increase shareholder value. Shareholders bear the costs of a governance intervention but, because they are residual claimants, they share its benefits with bondholders. It follows immediately that projects that need governance intervention will receive it only if leverage is sufficiently low so as to avoid a debt overhang problem. In contrast, there is no restriction upon the leverage of projects that require no governance intervention.

If the output of information systems were observable, firms that needed governance interventions would commit to a low level of debt. Doing so in our model is costly, because interest on debt is not subject to corporation tax. Hence, ceteris paribus, firms prefer to have a high level of leverage. Since the output of an information system is not verifiable, the headquarters is better informed about the firm's prospects than the outside investors. Headquarters with favorable information about their projects therefore naturally attempt to signal this fact to their investors and want to take on high levels of debt to save taxes. Headquarters with projects that require governance intervention have an incentive to pool, and when they do so, they assume so much debt that they never make governance interventions. When this happens, the social cost of requiring firms to implement an information system goes beyond the direct costs of implementation.

Our analysis therefore suggests that a regulatory requirement to implement an information system may impose costs on firms without improving the quality of their corporate governance. Firms might implement information systems, retain high levels of debt, and ignore the output generated by the information system. Consistent with this prediction, there is some evidence that firms do not always take the governance actions suggested by their information systems. For example, after Barings Bank collapsed in 1995 after sustaining losses of $£ 827$ as a result of unauthorized trading activity by Nick Leeson, the Bank of England stated in an official report that Barings failed to respond to a number of warning signals that its activities were poorly governed (Board of Banking Supervision 1995, pp. 124-128). More recently, the U.S. Senate report into the 2008-09 financial crisis included evidence that Washington Mutual ignored evidence of loan fraud uncovered in 2005 by an internal risk mitigation team (Permanent Subcommittee on Investigations 2011, pp. 96-98), and the U.S. Financial Crisis Inquiry Commission (2011, pp. 166-167) reports that an independent provider of third-party due diligence services found that major U.S. banks violated their own lending 
THE ADVERSE EFFECT OF INFORMATION ON GOVERNANCE AND LEVERAGE

standards in up to $42 \%$ of the loans they granted. ${ }^{3}$

In the absence of regulation, our model predicts that firms operating in industries that are subject to high levels of operational risk will have low levels of leverage, and will make general governance interventions. Because they intervene unselectively, such firms will make little or no investment in information systems. In industries that have little exposure to operational risk, our model predicts that firms will not invest in information systems and will never perform governance interventions. Firms operating in industries with intermediate levels of operational risk will invest in information systems that enable them to make governance interventions selectively, where they are most valuable.

We consider an extension to our model that is closer to some standard arguments against information production (see, for example, Rotemberg and Saloner (1994)). In the extension, managers must perform costly project search to identify a project. It is impossible to commit to compensate managers for project discovery, but firms are able to commit ex ante to a wage contract conditional upon project investment. In this set-up, information systems have two countervailing effects. On the one hand, as in the base case model, an information system allows the firm to allocate resources efficiently; on the other hand, a firm with an information system is able to condition its investment decision upon the project type. As a result, it may choose not to carry out manipulable projects that require costly governance intervention. This choice is anticipated ex ante, reduces the manager's incentives to search for a project, and so increases the compensation that must be paid to the manager of a non-manipulable project. The effect may be to reduce the expected value of a project, and so to render an information system undesirable. Thus, our analysis of managerial search costs highlights an additional potential cost of information systems.

\section{Related literature}

There is a large literature that demonstrates that more information can result in worse economic outcomes. Most importantly, more information can motivate undesirable actions in situations with incentive or commitment problems. For example, Crémer (1995) shows that, when it is easy to gather information about an agent's performance, the principal may be unable to commit to threats

\footnotetext{
${ }^{3}$ Figures for Citigroup, Credit Suisse, Deutsche Bank, Goldman Sachs, JP Morgan, Merrill Lynch, UBS and Washington Mutual are reported. The $42 \%$ figure refers to Citigroup; the lowest reported violation was for UBS, at $20 \%$.
} 
THE ADVERSE EFFECT OF INFORMATION ON GOVERNANCE AND LEVERAGE

that are ex ante useful. As a result, the principal may prefer a restricted information technology. Similarly, Aghion and Tirole (1997) present a model in which a principal may prefer to limit access to information so as to devolve real decision-making authority to an agent, who will work harder as a result. More recent work in this vein is due to Hermalin and Weisbach (2012), who analyze a model in which owners may elect to restrict information generation because managers capture some of its benefits in bargaining, and because it may induce managers to devote time to value-reducing activities that make them look more able. Hermalin and Weisbach's analysis therefore differs from ours in that it admits managerial manipulation of information. Arya, Fellingham, Glover, and Sivaramakrishnan (2000) present work related to our extension with costly project search. Like us, they consider a setting in which the firm commits to an information system before managers search for projects, and in which better information about project quality can reduce project search incentives. Dutta and Fan (2012) identify a similar problem in a model in which it is impossible for headquarters to commit ex ante to a managerial wage contract.

Drymiotes (2007) analyzes a model where it is ex ante optimal for shareholders to obtain more precise information about managerial effort; but ex post this information increases managerial compensation at the expense of shareholders. A dependent board whose interests are aligned with those of the CEO allows shareholders to commit to obtaining such information. In our model, headquarters might not take required actions if the firm is highly levered, and low leverage makes it optimal for headquarters to take actions to increase shareholder value and is a prerequisite for information to be optimal for shareholders (ex ante as well as ex post).

While the literature above is concerned about the effect of information between two parties that interact, our model focuses on the detrimental effect that the increase in information within the firm has on the interaction with a third party, which does not have this information readily available (outside investors). Producing more outside information is not a straightforward panacea. First, it may cause problems of its own. Pagano and Volpin (2012) demonstrate that more public disclosure may exacerbate insider trading problems that derive from adverse selection between corporate insiders and outsiders if some market participants are better placed to interpret the information than others. Second, producing such information can be difficult since headquarters can manipulate information and verification by auditors is costly, given that auditors are subject to moral hazard problems. Pae and Yoo (2001) analyze the interaction of internal audit systems with auditor effort as a function of the auditor's liability in the event that its reports prove to be 
THE ADVERSE EFFECT OF INFORMATION ON GOVERNANCE AND LEVERAGE

incorrect. Ramanan (2014) shows that improved governance (via a more diligent board) can reduce external auditors' incentives to monitor the audit report. We assume that auditors cannot verify the information that headquarters learns from an information system and headquarters can lie about the outcome of its information system.

\section{Model}

\subsection{Setting}

We consider a firm, comprising headquarters and management, and the firm's investors. The firm is endowed with a project. All parties are risk-neutral and have an outside option that yields an expected payoff of zero. We normalise the risk-free interest rate to zero. The headquarters acts in the interest of shareholders, but the manager might exert insufficient care or extract rents in such a way as to reduce the project's payoff. These are examples of operational risks, and we refer to them as shirking.

Operational risk in general, and shirking in particular, can be addressed by devoting resources to a governance intervention. Investors and the headquarters have a similar degree of understanding about the nature of the firm's project and the industry in which it operates; they therefore share a common prior over the firm's exposure to operational risk. The headquarters can invest in an information system that generates more precise information about the project's operational risk, but it is hard for outsiders to access and to interpret the system's output.

We capture these ideas in our model in the simplest possible way, by assuming, first, that the information system generates perfect information about the project's exposure to the risk of shirking; and, second, that the information system's output is the headquarters' private information.

\subsection{Project types, governance intervention, and information systems}

The project requires an investment of 1 . If the investment is made, the project can either succeed or fail, with corresponding payoffs $R$ and 0 . The project is run by a manager, who acts in his own interest. The project is exposed to operational risk: with probability $\mu$, the manager finds a way to shirk, diverting resources to increase his personal benefits and reducing the project's success probability. The probability $\mu$ captures the industry-specific nature of operational risk: when $\mu$ 
THE ADVERSE EFFECT OF INFORMATION ON GOVERNANCE AND LEVERAGE

is high, the firm operates in a business that is particularly subject to operational risks, such as banking; a lower $\mu$ applies to businesses in sectors like the textile industry that are less subject to operational risks.

If the project does not experience shirking, either because it is impossible or because the headquarters makes a governance intervention, then it has success probability П. Shirking, if possible and not prevented by a governance intervention, reduces the success probability to $\Pi-\Delta$. Without governance intervention, the project's a priori success probability is

$$
\pi \equiv \Pi-\mu \Delta
$$

The cost of a governance intervention is $k$. As discussed in the Introduction, the precise nature of the governance intervention is not important for most of our analysis. One simple way to think of the intervention is as the expenditure of additional monitoring resources equal to $k$ in order to prevent managerial fraud. An alternative way to model the intervention, which we employ in Section 4.4, is that headquarters pays a bonus to prevent the manager from shirking.

We call the project manipulable if the manager can find a way to shirk and non-manipulable if shirking is impossible. Shirking can be avoided on a manipulable project only if the headquarters makes a costly governance intervention to address the operational risk.

The headquarters can find out whether the project is manipulable only by implementing an information system, at a cost $\delta$. We denote the headquarter's decision to implement an information system by $\rho \in\{0,1\}$. A headquarters with an information system can condition its intervention decision upon whether or not the project is manipulable; without an information system, the headquarters must decide whether or not to intervene without knowing whether the project is manipulable. The information generated by the information system ranges from tacit information imparted through face-to-face meetings to codified accounting data. We assume that, because this information is complex and specialised, it cannot be credibly conveyed to third parties. As a result, although the implementation of an information system is observable, its output is not. Section 4.1 discusses the effect upon our results of assuming that the investment in information systems is not observable. 


\subsection{Financing}

If investment occurs, the headquarters uses a combination of debt and (internal) equity to finance the project. ${ }^{4}$ We assume that capital markets are competitive, so that the bondholders' participation constraint is binding and they expect to break even in equilibrium.

We denote the amount of debt raised (debt level) by $D$ and the promised debt repayment by $B<R$. The firm therefore pays interest $B-D$ on its debt. Both $D$ and $B$ are observed by bondholders. If the project is a success, the firm is able to honour the debt repayment obligation in equilibrium and pays $B$ to the bondholders. If the project fails, the payment to bondholders is zero.

The firm pays tax on its profits after the deduction of interest payments, $B-D$, and depreciation, which in our one-period model is equal to the initial investment of 1 . The marginal corporate tax rate is $\tau$ and the after-tax payoff in the success states is

$$
R-\tau(R-1-(B-D))=R_{\tau}+\tau(B-D),
$$

where, for ease of exposition, we write

$$
R_{\tau} \equiv R-\tau(R-1)
$$

for the after-tax payoff of an all-equity financed project. We do not consider personal taxation in our model and we normalise it to zero.

Because of the tax benefit of debt, the after-tax payoff in the success state increases in the debt level used to finance the project. We assume that the debt level is limited by the initial investment, i.e., $D \leq 1 .^{5}$ If $D<1$, equity of $1-D$ is used to finance the initial investment. 
THE ADVERSE EFFECT OF INFORMATION ON GOVERNANCE AND LEVERAGE

time 0

Headquarters decides

whether to spend $\delta$

to deploy an infor-

mation system. If it

deploys an informa-

tion system, then it

learns whether the

project is manipulable. time 1

Headquarters de-

cides whether

to invest. time 2

If investment occurs, then the

capital structure is selected and

funds are raised via a take-itor-leave-it offer to investors. time 3

Headquarters

decides whether

to incur the cost

$k$ of a governance

intervention.

If there is no governance

intervention then

a manager of

a manipulable

project can shirk.

Figure 1. Timing of the investment game. The headquarters decides whether to deploy an information system up front. It then decides whether to invest, selects a capital structure, and decides whether to make a governance intervention.

\subsection{Timeline and assumptions}

The timing of the game is illustrated in Figure 1. At time 0, the headquarters decides whether to implement an information system and deploys it, if it has one. It then decides whether or not to invest. If investment occurs, then the headquarters selects the debt level $D$ for the investment at time 2 and decides whether to make a governance intervention at time $3{ }^{6}$ If there is no governance intervention, then the managers of manipulable projects can shirk.

\section{Assumption 1.}

$$
\pi R_{\tau}-1+\tau(1-\pi)>0
$$

Assumption 1 implies that, without an information system, the project's net present value is positive if it is financed entirely with debt $(D=1)$ and the headquarters never makes a governance intervention: Without information, the project's success probability is $\pi$ when the firm never performs a governance intervention. Thus, when $D=1$ and $B=1 / \pi$, the expected tax benefit of debt financing is $\pi \tau(B-D)=\tau(1-\pi)$.

\footnotetext{
${ }^{4}$ We consider only equity and debt financing, which is without loss of generality in our two-state world. However, since the headquarters cannot commit to implement the governance intervention, the distinction between debt (senior fixed claim) and equity (variable junior claim) is nevertheless important despite the binary structure of our model. The reason is that the seniority of the claim affects the way that the costs and benefits of the governance action are shared between different claimants.

${ }^{5}$ The tax-deductability of debt renders $D>1$ optimal in some situations. Our analysis is simpler, and our qualitative results are not materially affected, if we rule this possibility out. In practice, higher debt levels may be ruled out by tax law, or by debt overhang problems.

${ }^{6}$ The distinction between time 2 and time 3 is for expositional convenience. We could derive our results in a world in which financing and governance choices were made simultaneously.
} 


\section{Assumption 2.}

$$
(\Pi-\Delta) R_{\tau}-1+\tau(1-(\Pi-\Delta))<0<\Pi R_{\tau}-1-k .
$$

Assumption 2 implies that, with an information system, a governance interventions should occur if the information system identifies a manipulable project. Specifically, when the project requires a governance intervention, it is optimal for an all-equity firm to perform the intervention and to invest in the project. Moreover, even accounting for the tax benefit of an entirely debt-financed firm, the investment has a negative net present value, and, hence, should not occur, without the governance intervention.

\section{Model Solution}

In this section, we look at the headquarters' choices of capital structure and governance intervention. In Subsection 3.1 we assume that the headquarters does not have an information system. In Subsection 3.2 we assume that the headquarters has an information system.

\subsection{No information system}

When the headquarters does not have an information system $(\rho=0)$, it cannot identify the project's type, and thus cannot condition governance intervention on whether the project is manipulable or non-manipulable. Hence, the most general strategy is to select a probability $q$ with which a governance intervention occurs. The project's success probability with strategy $q$ and $\rho=0$ is

$$
p(q)=\Pi-\mu(1-q) \Delta
$$

Bondholders cannot observe $q$, but they form rational expectations, so that Equation (5) is satisfied in a competitive market:

$$
D=p(q) B
$$

Given a debt level $D \leq 1$, the headquarters invests equity $1-D$. For $\rho=0$, the shareholder value 
$V_{0}(q, D)$ is

$$
\begin{aligned}
V_{0}(q, D) & =p(q)(R-B)-q k-(1-D)-p(q) \tau(R-1-(B-D)) \\
& =p(q)\left[R_{\tau}+\tau(B-D)-B\right]-q k-(1-D) .
\end{aligned}
$$

Substituting Condition (5) into Equation (6) yields Equation (7):

$$
V_{0}(q, D)=p(q) R_{\tau}-q k-1+\tau D(1-p(q))
$$

which is the net present value of an all-equity project plus the tax benefit of debt, $\tau D(1-p(q))$.

After the headquarters has raised debt $D$ and invested $1-D$ of shareholder funds, it selects the probability $q$ of a governance intervention so as to maximize shareholder value. This requirement yields the following incentive compatibility constraint:

$$
q \in \arg \max p(q)\left(R_{\tau}+\tau(B-D)-B\right)-q k .
$$

The headquarters chooses $q$ and $D$ to maximize Equation (7) for $V_{0}(q, D)$, subject to Condition (5) and the incentive constraint (8). Note that the right hand side of Equation (8) is linear in $q$ with coefficient

$$
\mu \Delta\left(R_{\tau}+\tau(B-D)-B\right)-k
$$

Hence, $q=1$ if and only if Equation (9) is greater than 0. This requirement is satisfied for a positive debt level $D=\Pi B$ whenever

$$
D \leq \bar{D}_{0} \equiv \frac{\Pi}{1-\tau(1-\Pi)}\left(R_{\tau}-\frac{k}{\mu \Delta}\right) \text { and } \bar{D}_{0} \geq 0
$$

If $\bar{D}_{0}<0$, it is not optimal for a fully equity-financed firm without an information system to perform a governance intervention, so that the headquarters never makes a governance intervention, and sets $D=1$. For $\bar{D}_{0}>0$, it is optimal for shareholders to perform a governance intervention whenever $D \leq \bar{D}_{0}$. We rule out uninteresting cases by assuming that

$$
\bar{D}_{0}<1
$$


Condition (10) states that the headquarters makes a governance intervention when the debt level is not too high. If Condition (10) were violated, the firm would run into a debt overhang problem whereby it was no longer optimal for shareholders to bear the cost $k$ of governance intervention since, in this case, that cost would exceed the shareholders' benefit of governance intervention $\mu \Delta\left[R_{\tau}+\tau(B-D)-B\right]($ Equation $(9)){ }^{7}$

The headquarters picks the highest $D$ consistent with its preferred $q$. Hence, the headquarters chooses either $\left(D=\bar{D}_{0}, q=1\right)$ or $(D=1, q=0)$.

When the headquarters sets $D=\bar{D}_{0}$ and $q=1$, the manager never shirks. Hence, the project's value to shareholders is

$$
V_{0}^{n s} \equiv V_{0}\left(q=1, D=\bar{D}_{0}\right)=\Pi R_{\tau}-1-k+\tau(1-\Pi) \bar{D}_{0}
$$

$V_{0}^{n s}$ comprises the project's net present value without shirking and full equity financing, $\Pi R_{\tau}-1$, less the cost of the governance intervention and plus the expected value of the debt tax shield.

When the headquarters sets $D=1$ and $q=0$, the manager shirks with probability $\mu$. Hence, the shareholder value generated by the project is

$$
V_{0}^{s} \equiv V_{0}(q=0, D=1)=\pi R_{\tau}-1+\tau(1-\pi)
$$

The headquarters sets $D=\bar{D}_{0}$ and performs a governance intervention when $V_{0}^{n s} \geq V_{0}^{s}$. This requirement is equivalent to Condition (14):

$$
\mu \Delta R_{\tau}-k \geq \tau\left((1-\pi)-(1-\Pi) \bar{D}_{0}\right)
$$

The headquarters can commit to perform a governance intervention only by reducing its borrowing level from 1 to $\bar{D}_{0}$. Condition (14) states that it elects to do so precisely when the resultant increase in after-tax payoff (without debt) outweighs the increased tax bill.

Lemma 1 characterises the headquarters' optimal monitoring and leverage choices $q^{*}$ and $D^{*}$ in terms of the probability $\mu$ that the project is manipulable.

Lemma 1. Suppose that the headquarters does not have an information system. Then there exists

\footnotetext{
${ }^{7}$ In general, the debt overhang problem can be overcome if bondholders finance part of the cost of the governance intervention. However, this would not be possible here as they could not enforce the investment in the governance intervention.
} 
$a \bar{\mu}_{0}$ such that

1. The headquarters borrows $D^{*}=\bar{D}_{0}$ to finance the project and makes a governance intervention $\left(q^{*}=1\right)$ if $\mu \geq \bar{\mu}_{0}$;

2. The headquarters finances the project entirely with debt $\left(D^{*}=1\right)$ and does not make a governance intervention $\left(q^{*}=0\right)$ if $\mu<\bar{\mu}_{0}$;

3. $\bar{\mu}_{0}$ is decreasing in $R, \Delta$ and $\Pi$, and is increasing in $k$ and $\tau$.

Proof. $\bar{\mu}_{0}$ is the unique $\mu \in(0,1)$ for which Condition (14) is satisfied with equality if such a $\mu$ exists, and is otherwise equal to 1. Parts 1 and 2 follow from the observation that the left hand side of Condition (14) is increasing in $\mu$ and the right hand side is decreasing in $\mu$. Condition (14) is more likely to be satisfied for higher $\mu$, which yields parts 1 and 2 . The comparative statics of part 3 are easily established by differentiating Condition (14); the only non-trivial case is the comparative static for $\tau$. Note that

$$
\frac{\partial}{\partial \tau}\left[\mu \Delta R_{\tau}-\tau(1-\pi)+\tau(1-\Pi) \bar{D}_{0}\right]=-\mu \Delta(R-1)-\left((1-\pi)-(1-\Pi) \bar{D}_{0}\right)+\tau(1-\Pi) \frac{\partial \bar{D}_{0}}{\partial \tau} .
$$

It then suffices to note that

$$
\frac{\partial \bar{D}_{0}}{\partial \tau}=-\Pi \frac{(\Pi R-1)+k(1-\Pi) /(\mu \Delta)}{(1-\tau(1-\Pi))^{2}}<0
$$

The intuition behind the first two parts of Lemma 1 is that, because the headquarters must intervene in all projects or none, it does so when the probability $\mu$ that shirking is possible is sufficiently high. Three effects drive the comparative statics of the third part of the Lemma 1 and make governance interventions more likely. First, operational risk is more important, because shirking has a higher impact when $R$ or $\Delta$ increases. Second, as $\Pi$ increases or $k$ decreases, the repayment obligation for a given $D$ becomes lower, so that the debt overhang problem is diminished. Third, a lower tax rate increases the after-tax profitability of the project and so strengthens incentives to perform a governance intervention.

We write $V_{0}^{*}$ for the maximal shareholder value without an information system:

$$
V_{0}^{*}=\max \left\{V_{0}^{s}, V_{0}^{n s}\right\}
$$


THE ADVERSE EFFECT OF INFORMATION ON GOVERNANCE AND LEVERAGE

$V_{0}^{*}$ is strictly positive, since, by Assumption $1, V_{0}^{s}=\pi R_{\tau}-1+\tau(1-\pi)>0$. It follows that the headquarters will always invest in the project.

\subsection{Information system}

Suppose that the headquarters implements an information system. Then it learns the project's type $t \in\{m, n\}$ (manipulable or non-manipulable). For convenience, we refer to a headquarters with a manipulable project as a "manipulable firm;" a headquarters with a non-manipulable project is a "non-manipulable firm." Bondholders cannot observe the outcome of the information system. Hence, the only information upon which bondholders can condition their beliefs over the project's type and the probability with which the headquarters prevents shirking is the firm's capital structure. Headquarters chooses the capital structure given the information that it derives from the information system. Thus, the headquarters plays a signaling game with bondholders at the financing stage. We search for Bayesian Nash equilibria that are robust to the Cho and Kreps (1987) Intuitive Criterion.

Definition 1. An equilibrium for the time 2 signaling game with an information system comprises the following elements:

1. a headquarters' decision $I(t) \in\{0,1\}$ to invest or not, predicated upon the headquarters' knowledge of project type $t$;

2. a headquarters' choice of capital structure $D(t)$ and bond face value $B(t)$ that depend upon the project type $t$;

3. a probability $q$ with which the headquarters performs a governance intervention for a manipulable project;

4. given the headquarters' choice $D(t)$ and $B(t)$, an assessment by bondholders of the probability $b(D, B)$ that the project is manipulable;

with the following properties:

1. the probability assessment $b$ is derived from the headquarters' choices $D(t)$ and $B(t)$ using Bayes' Law wherever possible;

2. $B(t)$ is the repayment level at which bondholders with belief $b(D, B)$ expect to break even;

3. $q, D(t)$, and $B(t)$ are a best response to the bondholders' belief $b$, given the project's type $t$; 
THE ADVERSE EFFECT OF INFORMATION ON GOVERNANCE AND LEVERAGE

4. the bondholders' belief $b$ satisfies the Intuitive Criterion on any off-equilibrium path. That is, it assigns zero probability to types that could not benefit from deviation under any possible bondholder belief.

A headquarters that has an information system knows whether shirking is possible, and so can condition both the capital structure and the governance intervention on this information. Bondholders only observe the debt level $D$ and repayment $B$, conditional upon which they form beliefs about the probability $b$ that the project is manipulable. Bondholders beliefs are formed using Bayes' Law where possible.

Lemma 2 demonstrates that, as in the case without an information system, the headquarters only makes a governance intervention if the debt level is not too high.

Lemma 2. When the headquarters has an information system $(\rho=1)$, it makes a governance intervention if the project is manipulable whenever the following condition on its debt level is satisfied:

$$
D \leq \bar{D}_{1} \equiv \frac{\Pi}{1-\tau(1-\Pi)}\left(R_{\tau}-\frac{k}{\Delta}\right)
$$

where $\bar{D}_{1}>\bar{D}_{0}$.

Proof. If the project is manipulable, then the headquarters selects the probability $q$ with which it makes a governance intervention to satisfy the following incentive compatibility constraint:

$$
q \in \arg \max \{\Pi-(1-q) \Delta\}\left(R_{\tau}+\tau(B-D)-B\right)-q k
$$

The curly-bracketed term in Equation (17) is a manipulable project's probability of success given q. The right hand side of Equation (17) is linear in $q$ with coefficient $\Delta\left(R_{\tau}-B+\tau(B-D)\right)-k$. The result follows immediately after setting $B=\frac{D}{\Pi}$.

Lemma 2 implies that, as in Section 3.1, the headquarters can convince bondholders that it will make governance interventions by limiting the debt it uses to finance the project. The maximal debt level $\bar{D}_{1}$ that is consistent with taking measures against shirking when the headquarters has an information system exceeds the corresponding debt level $\bar{D}_{0}$ when it does not. The reason is that it is possible for the headquarters to condition its governance intervention upon the information system's outcome. As a result, the information system increases the expected benefit of the 
THE ADVERSE EFFECT OF INFORMATION ON GOVERNANCE AND LEVERAGE

governance intervention, and the debt level at which the headquarters is still willing to intervene is correspondingly higher.

Proposition 1 identifies every possible equilibrium in the case where the headquarters has an information system.

Proposition 1. Suppose that the headquarters has an information system. Then there are two possible types of equilibria:

1. A unique Incentive Equilibrium in which the headquarters chooses $D=\bar{D}_{1}$ irrespective of the outcome of the information system, and makes a governance intervention if required. This equilibrium always exists.

2. There exists $\bar{\mu}_{1}$ such that, if $\mu \leq \bar{\mu}_{1}$, there is a continuum of Shirking Equilibria in which the headquarters never performs a governance intervention. For every $D_{h}>\bar{D}_{1}$,

(a) there is a pooling Shirking Equilibrium in which the headquarters sets $D=D_{h}$ irrespective of the outcome of the information system;

(b) there is a partially separating Shirking Equilibrium in which a headquarters with a manipulable project sets $D=D_{h}$ and a headquarters with a non-manipulable project mixes between $D=D_{h}$ and some $D=D_{l}$ with $\bar{D}_{1}<D_{l}<D_{h}$.

The proof of Proposition 1 appears in the Appendix.

A first important observation is that there exists no separating equilibrium. The reason is that a non-manipulable firm can use high leverage to save taxes. Hence, in any separating equilibrium, high leverage would be a positive signal about the project's type. But, in such an equilibrium, a manipulable firm could also increase shareholder value by choosing high leverage. Thus, a nonmanipulable firm cannot use its capital structure to signal its type. ${ }^{8}$

Second, the salient characteristic of all alternatives to the Incentive Equilibrium is that a manipulable firm selects a debt level in excess of $\bar{D}_{1}$, and, hence, the headquarters does not make the governance intervention. It is for this reason that we refer to this class of equilibria as Shirking Equilibria. ${ }^{9}$

\footnotetext{
${ }^{8}$ We show in the Appendix (Lemma 8) that separation is impossible even if the headquarters leaves money on the table and offers debt at favorable terms to bondholders. The reason is that, in contrast to standard signaling problems where the types are exogenously given, the headquarters with a manipulable project can affect the success probability through governance intervention. Incentives to imitate the leverage of a firm with a non-manipulable project are also driven by the desire to save the cost of intervention.

${ }^{9}$ Despite the taxation costs of equity issuance, pooling Shirking Equilibria can be sustained for indebtedness levels that are strictly less than 1 . These equilibria are sustained by the off-equilibrium belief $b=1$. This belief survives
} 
THE ADVERSE EFFECT OF INFORMATION ON GOVERNANCE AND LEVERAGE

In a high leverage pooling equilibrium, the headquarters does not perform a governance intervention on manipulable projects and, as a result, the cost of debt financing increases. The headquarters might be able to increase shareholder value by restricting its leverage to $\bar{D}_{1}$. At this leverage, a governance intervention is carried out for manipulable projects, which increases the project's success probability. As a result, bondholders assign probability 0 to the possibility of managerial shirking, and the cost of debt finance is reduced. This benefits even non-manipulable firms. Hence, with appropriate investor beliefs for higher $D$, a pooling equilibrium can therefore be sustained with $D=\bar{D}_{1}$.

The Incentive Equilibrium of part 1 of Proposition 1 is sustained by bondholders' off-equilibrium belief that shirking will happen for sure when $D>\bar{D}_{1}$. With this belief, the cost of funding for higher debt issuance is sufficiently high to deter higher levels of debt than $\bar{D}_{1}$.

For $\mu>\bar{\mu}_{1}$ the only equilibrium is the Incentive Equilibrium. The intuition is that the headquarters can always opt to set $D=\bar{D}_{1}$, in which case investors correctly assess success probability $\Pi$ for its project. If a non-manipulable firm were to use a higher debt level to signal its type, then a manipulable firm would attempt to pool, so as to achieve a low cost of debt and also a higher tax rebate. The pooling would lower the perceived quality of the non-manipulable firm; it would be prepared to accept the associated increase in the cost of debt in exchange for a reduced tax bill precisely when the proportion of manipulable firms was sufficiently low. A non-manipulable firm is indifferent between pooling at a higher or lower debt level when $\mu=\bar{\mu}_{1}$. For $\mu>\bar{\mu}_{1}$, a non-manipulable firm strictly prefers the lower debt level, so that only the Incentive Equilibrium is feasible.

When $\mu \leq \bar{\mu}_{1}$, there is a continuum of possible alternative equilibria. A headquarters with an information system accounts for the prevailing equilibrium, but cannot influence which of the equilibria in part 2 of Proposition 1 arises; it is impossible to state a priori that any of the candidate equilibria is more likely to arise than any other.

Lemma 3, which we prove in the Appendix, establishes comparative statics for $\bar{\mu}_{1}$ :

Lemma 3. The threshold level of operational risk $\bar{\mu}_{1}$ below which Shirking Equilibria exist is decreasing in $R$ and $\Delta$, and is increasing in $k$ and $\tau$.

the Intuitive Criterion: that criterion allows any off-equilibrium belief that assigns zero probability to any type that could not possibly benefit from the associated deviation under any belief. Since any type would benefit from the belief $b=0$, there are no restrictions in our model upon off-equilibrium beliefs and, as a result, there is a continuum of feasible pooling equilibria. 
THE ADVERSE EFFECT OF INFORMATION ON GOVERNANCE AND LEVERAGE

Non-manipulable firms are prepared to borrow more than $\bar{D}_{1}$ when the resultant reduction in taxation outweighs the higher cost of funding caused by pooling with manipulable firms that do not make a governance intervention. Higher levels of $R$ increase $\bar{D}_{1}$ without affecting the consequences of pooling and, as a result, they reduce the relative benefit of higher leverage and so lower the threshold $\bar{\mu}_{1}$. Similarly, a higher $k$ reduces $\bar{D}_{1}$ and so raises the relative attractiveness of pooling at higher $D$ and, with it, the threshold $\bar{\mu}_{1}$. Finally, increasing the effect $\Delta$ of operational risk raises $\bar{D}_{1}$ and also makes shirking more costly; both effects serve to render pooling at high $D$ relatively less attractive, and so to lower $\bar{\mu}_{1}$.

\subsection{Decision to deploy an information system}

We now consider the time 0 decision to spend $\delta$ to install an information system. Our first observation is that the headquarters never implements an information system when Shirking Equilibria exist in the continuation game with an information system.

Lemma 4. When $\mu \leq \bar{\mu}_{1}$ the headquarters does not implement an information system and never makes a governance intervention.

The proof of Lemma 4 appears in the Appendix, and proceeds as follows. First, we show that when $\mu \leq \bar{\mu}_{1}$, a headquarters with an information system has at least as high a surplus in Shirking Equilibria as it does in the Incentive Equilibrium. Second, we note that shirking without an information system saves the cost $\delta$ of an information system and, hence, is preferred to shirking with an information system. If the headquarters does not implement an information system, then it can choose between performing a governance intervention or not, but it cannot condition this information on whether the project is manipulable. The headquarters' expected surplus is therefore at least as high as in the Shirking Equilibrium and, from the first stage of the proof, is strictly higher than its expected surplus with an information system. Hence, the headquarters does not implement an information system for $\mu \leq \mu_{1}$. Finally, we show that $\bar{\mu}_{0} \geq \bar{\mu}_{1}$, so that the headquarters does not make a governance intervention in the continuation game without an information system.

Lemma 4 guarantees that, when $\mu \leq \bar{\mu}_{1}$ so that Shirking Equilibria exist, the headquarters never implements an information system irrespective of which equilibrium prevails in the continuation game. When $\mu>\bar{\mu}_{1}$ the continuation game with and without an information system has a unique equilibrium. It follows that, for each $\mu$, the headquarters has a strictly dominant time 0 strategy. 
THE ADVERSE EFFECT OF INFORMATION ON GOVERNANCE AND LEVERAGE

For $\mu>\bar{\mu}_{1}$ the Incentive Equilibrium of Proposition 1 obtains if the headquarters deploys an information system, and the shareholder value is given by Equation (18):

$$
V_{1}^{n s} \equiv \Pi R_{\tau}-1-(1-\Pi \tau) \delta-\mu k+\tau(1-\Pi) \bar{D}_{1}
$$

We compare this value to the shareholder value without an information system. First, if $\mu \leq \bar{\mu}_{0}$, the headquarters does not intervene in the continuation game without an information system and the shareholder value is $V_{0}^{s}$. The headquarters therefore deploys an information system precisely when $V_{1}^{n s} \geq V_{0}^{s}$. This requirement is equivalent to

$$
\mu\left(\Delta R_{\tau}-k\right) \geq(1-\Pi \tau) \delta+\tau\left((1-\pi)-(1-\Pi) \bar{D}_{1}\right)
$$

That is, the headquarters implements an information system in this case if the expected benefit $\mu\left(\Delta R_{\tau}-k\right)$ of preventing shirking in an all-equity firm exceeds the combined costs of the information system and the loss in tax benefit caused by the lower debt level in the Incentive Equilibrium. We write $\mu_{1}^{\min }$ for the value of $\mu$ at which Condition (19) is satisfied with equality.

Second, if $\mu>\bar{\mu}_{0}$, the headquarters intervenes in every project, and the shareholder value is $V_{1}^{s}$, in the continuation game without an information system. In this case, the headquarters deploys an information system precisely when $V_{1}^{n s} \geq V_{0}^{n s}$, which is equivalent to

$$
(1-\mu) k+\tau(1-\Pi)\left(\bar{D}_{1}-\bar{D}_{0}\right) \geq(1-\Pi \tau) \delta
$$

The information system is optimal in this case if the expected cost saving of not performing a governance intervention on non-manipulable projects and the tax benefit from the higher debt level

with an information system exceeds the after-tax cost of the information system. We define $\mu_{1}^{\max }$ to be the $\mu$ for which Condition (20) holds with equality (it is easy to show that $\mu_{1}^{\max }$ exists and is unique for any $k>0$ ). Condition (20) reduces to the requirement that $\mu<\mu_{1}^{\max }$.

Proposition 2 characterises the headquarters' information system deployment decision.

\section{Proposition 2.}

1. If $\mu \leq \min \left(\mu_{1}^{\min }, \bar{\mu}_{0}\right)$ then the headquarters sets $D=1$, does not implement an information system, and never makes a governance intervention;

2. If $\min \left(\mu_{1}^{\min }, \bar{\mu}_{0}\right)<\mu \leq \max \left(\mu_{1}^{\max }, \bar{\mu}_{0}\right)$ then the headquarters sets $D=\bar{D}_{1}$, implements an 


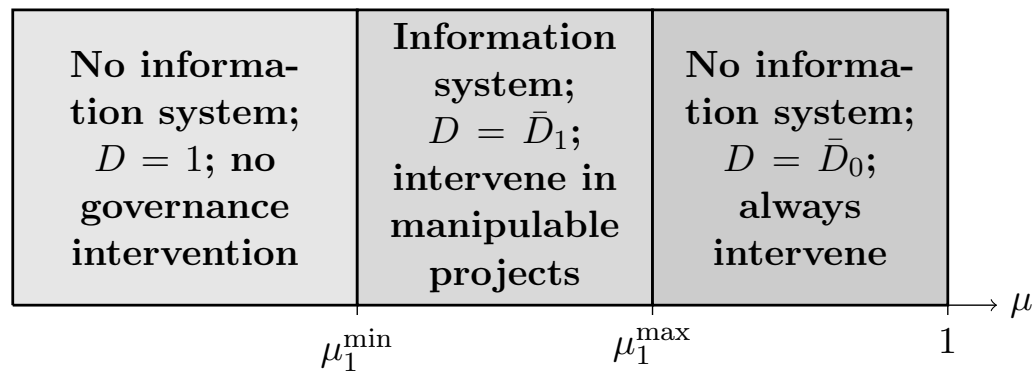

Figure 2. Equilibrium map for the headquarters time 0 decision. When the likelihood of shirking is very low, the headquarters does not pay for an information system and assumes as much debt as possible. When shirking is very likely, the headquarters does not buy an information system, and always intervenes; for intermediate shirking likelihood, the headquarters implements an information system so that it can intervene selectively.

information system, and performs a governance intervention if the project is manipulable;

3. If $\mu>\max \left(\mu_{1}^{\max }, \bar{\mu}_{0}\right)$ then the headquarters sets $D=\bar{D}_{0}$, does not implement an information system, and always performs a governance intervention.

Proof. Part 1 of the Proposition follows from Lemma 4 and from the definition of $\mu_{1}^{\min }$. For part 2 , recall that the headquarters implements an information system if either $\mu_{1}^{\min }<\mu<\bar{\mu}_{0}$ or $\bar{\mu}_{0}<\mu<\mu_{1}^{\max }$. Finally, if $\mu>\bar{\mu}_{0}$ and $\mu>\mu_{1}^{\max }$, then the headquarters does not implement an information system and instead always intervenes.

The headquarters' decision depends upon the probability $\mu$ that the manager finds a way to shirk. When $\mu$ is very low, as in part 1 of the Proposition, there is little to be gained from making a governance intervention, and the headquarters prefers to maintain a high debt level and not to spend $\delta$ on an information system. When $\mu$ is higher, the headquarters prefers to avoid shirking. It then faces a choice between spending $\delta$ on an information system that allows for selective governance interventions, and avoiding that expenditure but intervening unselectively. The former approach dominates for intermediate values of $\mu$, as in part 2 of the Proposition. When $\mu$ is very high, as in part 3 of the Proposition, it is very likely that the project requires intervention: in this case, it is more cost-effective for the headquarters not to implement an information system, and instead always to intervene.

The equilibrium regions identified in Proposition 2 are mapped in Figure 2 for the case where $\mu_{1}^{\min }<\bar{\mu}_{0}<\mu_{1}^{\max }$. Note that the region identified in part 2 of the Proposition may be empty. For example, when the cost $k$ of intervention is sufficiently low, the headquarters no longer finds it worthwhile to spend $\delta$ on an information system that allows it to distinguish between cases where 
THE ADVERSE EFFECT OF INFORMATION ON GOVERNANCE AND LEVERAGE

intervention is, and is not, required.

This discussion generates the following corollary to Proposition 2.

Corollary 1. There exist equilibria in which the headquarters invests in an information system only when the cost $\delta$ of the information system is sufficiently low, and when the cost $k$ of intervention is sufficiently high.

\subsection{Empirical predictions and implications}

Our main results relate the probability $\mu$ that shirking is possible to the decision $\rho$ to implement an information system and to the firm's leverage $D$. It is possible to test those results only if $\mu, \rho$, and $D$ can be measured. A swathe of corporate finance papers quantify indebtedness, and we therefore take it for granted that $D$ can be measured.

Much of our model assumes that outside observers can tell whether a firm has implemented an information system. Of course, all firms generate a certain amount of information. Our assumption is that only some firms generate sufficient information to identify potential governance failings and that reports by auditors and other third parties will reveal the existence of those systems.

The probability $\mu$ that a project is manipulable is harder for the econometrician to measure. The problem is that, precisely because the firm can perform governance interventions to prevent shirking, $\mu$ cannot be identified with the frequency with which operational risk manifests itself. We are therefore left with the need to identify plausible proxies for $\mu$. In practice, we believe that the complexity of a business is a good indicator of its susceptibility to operational risk of projects undertaken within that business. This is in line with work by the Basel Committee on Banking Supervision (2011, p. 4, 12), and with Bushman, Chen, Engel, and Smith (2004), who exhibit evidence relating compensation-based incentives to organizational complexity. Hence, one could attempt to proxy for $\mu$ in tests of our hypotheses with a standard measure of organizational complexity: in their paper, Bushman, Chen, Engel, and Smith (2004) use industry and geographic concentration as proxies for complexity.

Proposition 2 identifies the relationship between information system adoption and the likelihood $\mu$ that a governance intervention is required. It should be possible to use our suggested proxies for the likelihood $\mu$ that a project is manipulable to test Hypothesis 1:

Hypothesis 1. There is a non-linear relation between information system adoption and the likeli- 
THE ADVERSE EFFECT OF INFORMATION ON GOVERNANCE AND LEVERAGE

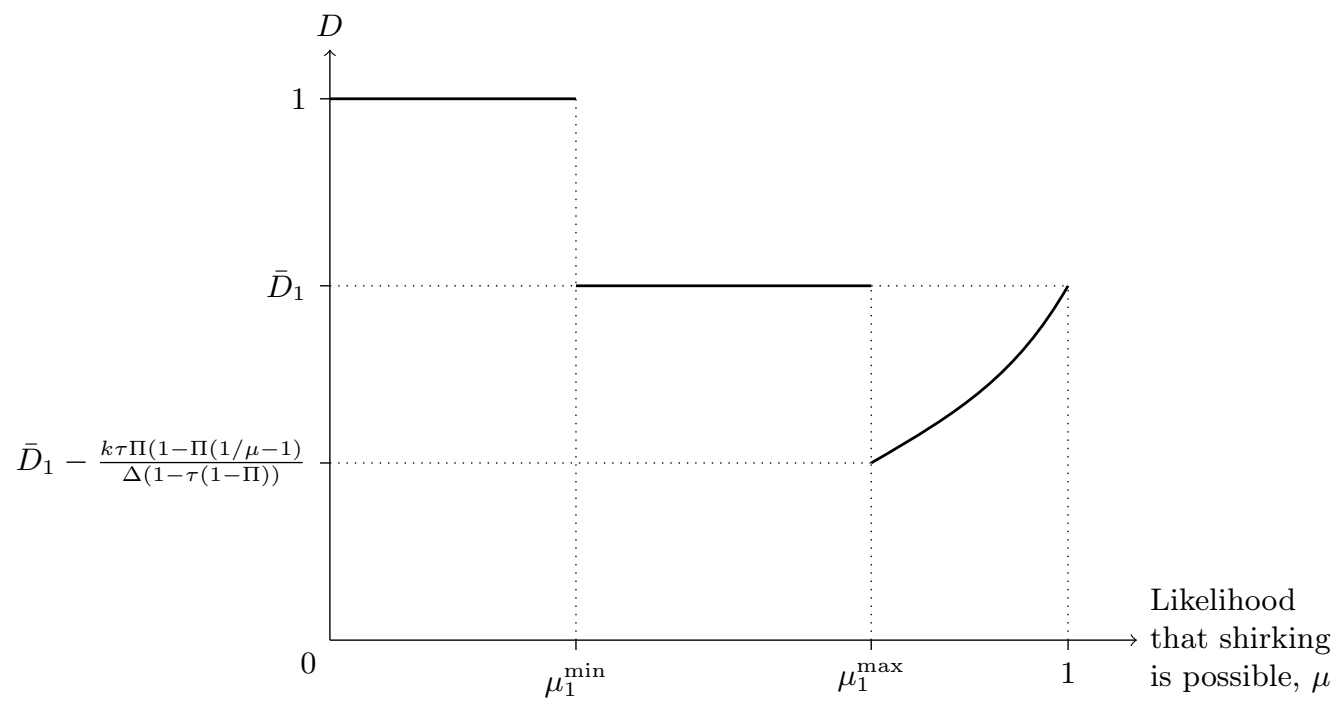

Figure 3. Equilibrium level of debt and shirking likelihood. The three regions in this Figure correspond to parts 2(a), (b) and (c) of Proposition 2.

hood $\mu$ that operational risk arises: firms with low and high $\mu$ values do not implement information systems, while those with intermediate $\mu$ values do.

In Figure 3, we plot the level of indebtedness predicted by Proposition 2 against the likelihood $\mu$ that shirking is possible. Note that, while $\bar{D}_{1}$ is independent of $\mu, \bar{D}_{0}$ is increasing in $\mu$. Hence, our model does not predict a monotonic relationship between levels of indebtedness and susceptibility to shirking. We obtain the following hypothesis:

\section{Hypothesis 2.}

1. The lowest and highest levels of debt are observed amongst firms that have no information system. Firms with information systems have intermediate levels of debt.

2. Amongst firms that have no information system and whose debt level is below that of firms with an information system, indebtedness is increasing in the susceptibility $\mu$ to shirking.

3. Amongst firms with information systems, indebtedness is not sensitive to the susceptibility $\mu$ to shirking.

Our model allows us to examine the effects of tax rates upon operational risk and information system adoption. Higher tax rates render leverage more attractive and, hence, render shirking at a higher level of leverage relatively more attractive. This yields the following hypothesis:

Hypothesis 3. High taxation economies are more likely to experience operational risk incidents. 
THE ADVERSE EFFECT OF INFORMATION ON GOVERNANCE AND LEVERAGE

\subsection{Regulatory implications}

Our analysis to this point has assumed that there is no regulatory requirement to implement an information system. In this section, we use our model to consider the possible costs and benefits of such a requirement. Our conclusions depend upon which of the regions of Figure 2 arises absent regulation.

An important rationale for compelling information system implementation is that it should improve corporate governance when firms do not implement a system voluntarily, and never perform a governance intervention. This is the case in the leftmost region of Figure 2. But compulsory information system adoption need not increase governance interventions: if $\mu<\bar{\mu}_{1}$ then the continuation game with an information system could have a Shirking Equilibrium, in which case compulsory information system implementation would expose the firm to the cost $\delta$ without inducing any ad-

ditional governance interventions. An Incentive Equilibrium is guaranteed when $\bar{\mu}_{1}<\mu<\mu_{1}^{\min }$ and is possible for $\mu<\bar{\mu}_{1}$; compulsory information system implementation would result in more governance interventions in this case. As in part 1 of Proposition 2, the headquarters judges an information system to add less value than its $\operatorname{cost} \delta$ for these low values of $\mu$. The higher level of intervention achieved by forced information system implementation would therefore come at a very high cost, and possibly with no benefit.

The middle region of Figure 2 obtains absent regulation when $\min \left(\mu_{1}^{\min }, \bar{\mu}_{0}\right)<\mu \leq \max \left(\mu_{1}^{\max }, \bar{\mu}_{0}\right)$. In this case, the headquarters implements an information system voluntarily, and a regulation mandating information system implementation therefore has no effect at all.

Finally, suppose that $\mu>\max \left(\mu_{1}^{\max }, \bar{\mu}_{0}\right)$, as in the rightmost region of Figure 2. In this case, an unregulated firm does not implement an information system, and always performs a governance intervention. Forcing the firm to implement an information system renders its governance interventions selective, so that the total number of interventions drops. Although implementing an information system exposes the firm to costs that it would prefer to avoid, it has no effect in our model upon the quality of governance, because the firm continues to intervene whenever intervention is needed. But a small modification to our base assumptions would alter this conclusion. Suppose, contrary to our main model, that even a non-manipulable project could experience shirking with some probability so low that, if it knew the project's type, the headquarters would never elect to intervene in it. In that case, in addition to imposing costs upon the firm, forcing information system 
THE ADVERSE EFFECT OF INFORMATION ON GOVERNANCE AND LEVERAGE

implementation would also increase the expected level of managerial shirking, because intervention in non-manipulable projects would no longer occur.

In summary, our analysis indicates potential costs and unintended consequences of forcing firms to implement information systems to address agency problems within the firm. Doing so imposes significant costs upon regulated entities and, rather than solving informational problems, such systems may simply shift them from within the firm to its boundary, so that the quality of governance might not improve.

The SEC (2009) examines direct costs of Section 404 compliance, which includes the costs of creating adequate information systems. The direct costs are increasing in company size, and decreasing in the company's experience of Sarbanes-Oxley reporting. Median direct compliance costs range from $\$ 439,460$ for firms with a float of less than $\$ 75 \mathrm{mn}$ to $\$ 1.99 \mathrm{mn}$ for firms with a public float in excess of $\$ 700 \mathrm{mn}$. These costs are substantial, but our paper demonstrates that they may be to no avail, because they create an incentive to signal the results of hard-tointerpret internal information systems. Indeed, we have argued that, with a small modification to our base assumptions, implementing compulsory information systems could even reduce the quality of corporate governance. In line with this argument, there is evidence that firms voted with their feet after the passage of the Sarbanes-Oxley Act. Leuz, Triantis, and Yue Wang (2008) identify a spike in SEC deregistrations that is due to increased compliance costs after the passage of SarbanesOxley, and Li (2014) argues that cross-listing on US exchanges became significantly less attractive for foreign firms after the passage of Sarbanes-Oxley.

\section{Extensions and Robustness}

\subsection{Observability of information system}

In our analysis so far, the headquarters' time 0 information system deployment is observable. We now consider a modification of our results in which the information system is not observable. An equilibrium of the modified game comprises (1) an investor belief as to whether an information system was deployed, and (2) headquarters' decisions over information system deployment, governance interventions, and leverage, such that (i) the headquarters' decisions are the optimal response to the investors' belief; and (ii) the investors' belief is correct.

Proposition 3 characterizes the equilibrium in this case: 
THE ADVERSE EFFECT OF INFORMATION ON GOVERNANCE AND LEVERAGE

Proposition 3. There exists a $\bar{\mu}^{u}$ such that:

1. If $\mu \leq \bar{\mu}^{u}$ then the headquarters sets $D=1$, does not implement an information system, and never makes a governance intervention;

2. If $\bar{\mu}^{u}<\mu \leq \mu_{1}^{\max , u} \equiv 1-(1-\Pi \tau) \delta / k$ then the headquarters sets $D=\bar{D}_{1}^{u}$, where

$$
\bar{D}_{1}^{u}=\bar{D}_{1}-\frac{\Pi(1-\Pi \tau) \delta}{(\Pi-\pi)(1-\tau(1-\Pi))}
$$

implements an information system, and performs a governance intervention if the project is manipulable;

3. If $\mu>\mu_{1}^{\text {max,u }}$ then the headquarters sets $D=\bar{D}_{0}$, does not implement an information system, and always performs a governance intervention.

The proof of Proposition 3 appears in the Appendix.

Proposition 3 for the case with unobservable information systems is the analogue to Proposition 2 for the case where information systems are observable; its equilibrium map is analogous to Figure 2.

The basic intuition behind Proposition 3 is similar to the intuition for Proposition 2. Once again, the headquarters will never wish to intervene, and, hence, will not pay for an information system, if the likelihood $\mu$ of shirking is low. When shirking is sufficiently likely to warrant governance interventions, the headquarters must again choose whether or not to pay for an information system that enables selective intervention. The headquarters uses an information system only when the after-tax benefit $k(1-\mu)-(1-\Pi \tau) \delta$ of doing so is sufficiently high: when it is not, the headquarters reverts to the debt level $\bar{D}_{0}$ and intervenes in every project.

As for Proposition 2, the region $\bar{\mu}^{u}<\mu<\mu_{1}^{\max , u}$ is non-empty only when information systems are not too expensive and intervention is costly.

The most important difference between the cases with observable and unobservable information systems is that the level of debt that can be sustained with an information system is lower when information systems are unobservable than when they are not: that is, $\bar{D}_{1}^{u}<\bar{D}_{1}$. The reason is that, when information system deployment is unobservable, investors cannot condition their beliefs upon whether deployment has occurred. The headquarters could therefore decide not to invest in an information system if investors believed that shirking would not occur. Doing so would enable the 
THE ADVERSE EFFECT OF INFORMATION ON GOVERNANCE AND LEVERAGE

headquarters to reap the benefits of interest tax deductibility and to save the cost of a governance intervention, while paying a low interest rate. This temptation introduces an additional incentive constraint for headquarters, which serves to lower the maximal debt level from $\bar{D}_{1}$ to $\bar{D}_{1}^{u}$.

\subsection{External and internal governance mechanisms}

So far, we have assumed that it is impossible to punish a firm for failing to take governance actions. In this section, we briefly consider the effect of relaxing this assumption and allowing penalties to be levied upon firms that do not take necessary governance actions. This analysis therefore allows us to consider possible interactions between external and internal governance mechanisms. This analysis is relevant to legislation like the Sarbanes-Oxley Act that aims to strengthen external governance by making it harder for the headquarters to argue that it did not know of a potential governance problem and, hence, facilitates the ex post punishment of governance failures.

Suppose that a firm's project type and governance choices are revealed ex post with probability $\alpha$, and assume that, in the case where a manipulable project did not receive a governance intervention, the firm incurs a punishment cost $P . \quad P$ could be a monetary cost imposed by the state; in a more complex repeated game, it could be the endogenous cost of losing a reputation for adequately managing governance problems. We can think of the probability of detection $\alpha$ as reflecting the quality or the intensity of an external auditor's effort. The expected cost $\alpha P$ of not performing a governance action strengthens the headquarters' incentives to take a governance action and so increases the maximum debt level consistent with governance interventions. Hence, if the probability $\alpha$ of detection or the associated penalty $P$ is high enough, the headquarters chooses to implement governance actions even if the firm is entirely financed with debt; this is similar to the case in our main model when the project has a very high net present value.

This discussion yields an interesting cross-sectional implication: ceteris paribus, leverage will be higher in countries that impose higher legal penalties for not implementing necessary governance interventions. Moreover, it identifies a link between external and internal governance. Good external governance enables the firm to commit not to strategically exploit its information advantage; it therefore makes governance interventions more likely. However, the interaction between internal and external governance is complex (see Drymiotes (2007) and Ramanan (2014)) and a complete analysis is outside the scope of this paper. For example, if the firm anticipates a high level of auditor 
THE ADVERSE EFFECT OF INFORMATION ON GOVERNANCE AND LEVERAGE

scrutiny, it is less likely to shirk on internal governance measures. But this effect serves in turn to undermine the auditor's incentives to exert effort, and so cause the firm's internal governance incentives to unravel. A fuller model must therefore incorporate either mixed auditing incentives or some source of noise.

In addition, we cannot conclude that higher penalties $P$ are necessarily welfare-enhancing. A more complete analysis would have to account for the systemic costs of higher economy-wide levels of leverage, and also for the possibility that penalties are imposed with error.

\subsection{Costs of financial distress}

In this section, we consider how our results would be affected if we included costs of financial distress in our analysis. Such costs arise when bankruptcy or the imminent risk of bankruptcy cause reductions to the firm's free cash flow that would not otherwise have occurred. For example, when managers believe that bankruptcy is possible, their operational decisions may be distorted, and they may perform asset fire sales; after bankruptcy occurs, these effects are augmented by the legal costs of enforcing claims.

All financial distress costs reduce the amount of money available for debt servicing. Bondholders anticipate these costs and adjust their participation constraint accordingly: the costs of financial distress are therefore borne ex ante by shareholders. The costs of financial distress are increasing in the level of debt outstanding and introduces an additional marginal cost of debt, which has the following effects in our model.

First, when financial distress is sufficiently costly, the optimal debt level without governance intervention is less than one. Indeed, when the costs of financial distress are sufficiently high, the constraints $D \leq \bar{D}_{0}$ and $D \leq \bar{D}_{1}$ may no longer be binding, in which case there is no longer a conflict between increasing debt to save taxes and incentives to perform governance interventions.

Second, costly financial distress renders governance interventions more valuable. The headquarters is therefore relatively more willing to assume low levels of debt so as to signal that governance interventions occur.

These effects together serve to render governance interventions more likely when financial distress is costly. The qualitative features of our results are otherwise unchanged.

In this setting, separating equilbria do not exist because debt holders bear the ex post costs 
THE ADVERSE EFFECT OF INFORMATION ON GOVERNANCE AND LEVERAGE

of failure and can only be compensated for them ex ante in expectation. As a result, manipulable firms have an ex post incentive to pool with non-manipulable firms, so as to impose uncompensated costs upon bondholders. If the headquarters experienced a high ex post personal cost of distress, for example as a result of reputation loss, then separating equilibria might be possible.

\subsection{Information systems and managerial search incentives}

In this section we extend our analysis by requiring managers to search for projects at time 0.5 , after headquarters has decided whether to implement an information system. The manager finds a project with probability 1 if he incurs a private search cost $c>0$, and does not find a project otherwise.

In this section, we model an explicit form of governance intervention, assuming that the manager can extract a private benefit $\beta$ from shirking, in line with the discussion in the Introduction. The manager is protected by limited liability and has an outside opportunity of zero, so that, absent any danger of shirking, the headquarters pays the manager a flat wage of 0 . The governance intervention

involves the payment of a bonus $w_{M}$ in the case of project success to induce the manager to give up the private benefit of shirking. The bonus prevents shirking if the expected wage increase $\Delta w$ that the manager derives from not shirking exceeds the private benefit $\beta$ of shirking. It follows that the headquarters pays a success bonus $w_{M}=\beta / \Delta$. The cost of this intervention to shareholders is the expected after-tax bonus payment: $k=\Pi(1-\tau) w_{M}$.

If firms respond to governance problems by implementing performance-related pay, then bonus payments should be lower when leverage is high, because high leverage undermines the incentive to resolve governance problems. This conclusion is consistent with Ortiz-Molina's (2007) finding that pay-performance sensitivity decreases in leverage.

\subsubsection{Commitment / complete contracts}

We first assume that the headquarters is able to write a wage contract at time 0 that is contingent on both project discovery and project success. We write $w_{P}$ for the discovery bonus that the manager is paid upon finding a project. The manager searches for a project if his total ex ante expected payoff from finding and carrying out a project exceeds his search cost $c$. Because the manager anticipates earning some rent from projects that he manages, the required discovery bonus is less than $c$. We 
THE ADVERSE EFFECT OF INFORMATION ON GOVERNANCE AND LEVERAGE

consider in turn the possible equilibria identified in Proposition 2.

1. Information system and governance intervention for manipulable projects. The manager is paid a success bonus when managing a project where shirking is possible, which results in an ex ante expected wage of $\mu \Pi w_{M}$ if the manager finds a project. Hence, the minimum discovery bonus that incentivises project search is $w_{P}^{1, n s}=\max \left\{0, c-\mu \Pi w_{M}\right\}$.

2. No information system and never governance intervention. The manager does not receive a success bonus, but derives a private benefit $\beta$ if shirking is possible, so that his expected benefit is $\mu \beta$ when finding a project. The minimum discovery bonus $w_{P}$ that induces managerial search is therefore $w_{P}^{0, s}=\max \{0, c-\mu \beta\}$.

3. No information system and always governance intervention. The manager receives a success bonus irrespective of the project's type and does not shirk. His expected wage after finding a project is therefore $\Pi w_{M}$. The minimum discovery bonus that induces project search is now $w_{P}^{0, n s}=\max \left\{0, c-\Pi w_{M}\right\}$.

Note that, since $\Pi w_{M}>\beta, w_{P}^{0, s}>w_{P}^{1, n s}>w_{P}^{0, n s}$; that is, the discovery bonus is decreasing in the expected rent (bonus) the manager earns when managing a project. As a result, the range of parameters for which it is optimal for the headquarters to pay a bonus to prevent shirking is greater with project search than without project search.

Proposition 4. When search is costly and the headquarters is able to commit to a wage contract at time 0 , the headquarters is more likely to prevent shirking than without costly search.

Proof. Consider the choice between shirking without an information system and not shirking with an information system. The latter is preferred precisely when

$$
V_{0}^{s}-(1-\tau) \max \{0, c-\mu \beta\} \leq V_{1}^{n s}-(1-\tau) \max \left\{0, c-\mu \Pi w_{M}\right\}-(1-\Pi \tau) \delta
$$

When $c=0$ this requirement reduces to $V_{0}^{s} \leq V_{1}^{n s}-(1-\Pi \tau) \delta$. Select parameters that make this condition bind. Then, because $\Pi w_{M}>\beta$, we can select $c$ such that $\mu \beta<c$; doing so slackens Condition (22) and so increases the parameter range for which shirking is prevented. 


\subsubsection{No commitment / incomplete contracts}

We now assume that it is not possible to write a compensation contract that is conditional upon project payoff before a project has been identified or that is contingent upon project discovery or investment. This assumption is appropriate in situations where contextual information about the project will be established only when search occurs. Perhaps no contract can perfectly capture the difference between success and failure in a complex corporate financial setting, but a contract that is written with a more complete understanding of the underlying business will be more effective. When an investment occurs, it is observable and could be the basis of a contract. But, for such a contract to provide effective search incentives, the agent who identified the investment must be easily identifiable by a court to enforce the compensation contract.

The assumption implies that it is impossible to write an explicit contract to reward the manager for project search. As a result, he will exert search effort only if he expects to earn a sufficiently high rent from managing the project. We again consider the three possible equilibria of Proposition 2 .

1. Information system and governance intervention for manipulable projects. The manager searches for a project if $\mu \Pi w_{M} \geq c$.

2. No information system and never governance intervention. The manager searches for a project if $\mu \beta \geq c$.

3. No information system and always governance intervention. The manager searches for a project if $\Pi w_{M} \geq c$.

The shareholder value is positive if and only if the manager searches for a project. Thus, the following Proposition is an immediate consequence of the above analysis:

Proposition 5. When search is costly and the headquarters is not able to commit to a wage contract, it is optimal for headquarters not to have an information system if Condition (14) is satisfied and

$$
\mu \Pi w_{M}<c<\Pi w_{M}
$$

Proposition 5 identifies conditions under which the manager exerts search effort when the headquarters does not have an information system, but does not if an information system is in place. In this case, it is optimal for headquarters not to implement an information system. In the absence of 
THE ADVERSE EFFECT OF INFORMATION ON GOVERNANCE AND LEVERAGE

commitment to wages, the headquarters decides to not implement an information system in order to guarantee a sufficient managerial rent to incentivise project search.

Proposition 5 describes a situation in which search costs combined with limitations on contractual commitment can induce the headquarters to switch from a policy of implementing an information system to one of not doing so. A switch from not implementing to implementing an information system is also conceivable. Suppose that the headquarters would not prevent shirking when it has no information system. Introducing search costs may lowers the manager's rent to such an extent that search stops. If $\mu \Pi w_{M}>c$ then the headquarters can induce search again, and so earn a positive income, by acquiring an information system.

\subsection{Multiple projects}

Our analysis concerns a firm with a single project. The headquarters in our model makes a governance intervention if it has a sufficiently high equity stake (see Lemma 1 and Proposition 1). This setting is similar to standard principal agent effort incentive problems in which the agent exerts effort if he receives a sufficiently high share of the proceeds of success. In this section, we consider the effect upon our results of an extension to multiple projects.

When multiple projects with uncorrelated payoffs are combined and the headquarters does not implement an information system, Laux's (2001) analysis of incentives in multiple projects is directly applicable in our setting: the headquarters needs less equity to incentivise precautionary governance actions for all projects. ${ }^{10}$ Hence, the debt-overhang problem can be ameliorated by combining projects. This effect is strengthened if some projects do not require governance intervention.

It is critical in Laux's (2001) analysis that the agent does not observe the realisation of one project before selecting the effort level on another. The reason is that an agent with this information can respond strategically to a negative payoff realisation on one project by withdrawing effort from others. This assumption is violated in our setting with an information system. Furthermore, the problem is complicated in our model by the fact that the agent does not only decide whether to make a governance intervention, but also selects the debt level, which affects incentives to perform a governance intervention. Moreover, in our setting, the leverage choice signals the quality of the firm's portfolio of projects.

\footnotetext{
${ }^{10}$ See also Cerasi and Daltung (2000), who present a model in which banks can commit to a higher level of monitoring by diversifying their portfolios and financing it with debt.
} 
THE ADVERSE EFFECT OF INFORMATION ON GOVERNANCE AND LEVERAGE

To see how this effect plays out, assume that the headquarters has two projects of the type described in our model. Then, if headquarters implemented an information system, there are three distinct elements to the headquarters' information space, corresponding to the cases where zero, one or two projects require a governance intervention. The maximum debt level that is consistent with governance intervention is decreasing in the number of projects that require intervention; it is $D=2$ when no governance intervention is required. Hence, the headquarters can set $D=2$ to signal the high quality of its projects even when one or two projects requires intervention; when it does so, no intervention occurs. Bondholders anticipate this effect, and price the firm's debt accordingly. Equilibria when governance interventions occur require the firm to reduce its debt level even when no governance intervention is required. Thus, the trade-off in the multi-project case resembles the trade-off in the one-project case.

\section{Conclusion}

This paper demonstrates that information systems can have detrimental incentive effects. We analyse the effect upon a firm's corporate governance of an internal information system whose results cannot be interpreted by outside investors. The information system therefore creates new asymmetric information between corporate insiders and outside investors. Insiders can use the firm's capital structure to signal the information that they acquire from their information system; we demonstrate that, as a result, there is a continuum of equilibria with an information system in which manipulable firms pool with non-manipulable firms at high levels of indebtedness. The indebtedness renders it uneconomic for shareholders to make governance interventions and, as a result, the information system is not used to reduce managerial shirking when this type of pooling occurs.

We identify the conditions under which firms in this set-up elect to invest in an information system. Firms do not invest in an information system when their projects are either very likely to experience shirking (since it is cheaper in that case to intervene indiscriminately than to implement an information system), or very unlikely to do so (since in this case the cost of addressing shirking outweighs the benefits). We show in addition that the headquarters will never voluntarily implement an information system in cases where Shirking Equilibria exist.

Our work yields a number of empirical predictions. It also points to various problems with a 
THE ADVERSE EFFECT OF INFORMATION ON GOVERNANCE AND LEVERAGE

policy that mandates information system implementation. Such a policy may expose the firm to high costs without affecting the quality of its corporate governance at all; we argue that it may even reduce the quality of the firm's governance.

\section{References}

Aghion P, Tirole J (1997) Formal and real authority in organizations. J. Pol. Econ. 105(1): 1-29.

Arya A, Fellingham J, Glover J, Sivaramakrishnan K (2000) Capital budgeting, the hold-up problem and information system design. Management Sci. 46(2): 205-216.

Basel Committee on Banking Supervision, 2011, Operational risk - supervisory guidelines for the Advanced Measurement Approaches, Discussion paper, June, Bank for International Settlements, Basel.

Board of Banking Supervision, 1995, Report of the Board of Banking Supervision inquiry into the circumstances of the collapse of Barings (Bank of England).

Bushman R, Chen Q, Engel E, Smith A (2004) Financial accounting information, organizational complexity and corporate governance systems. J. Accounting and Econom. 37(1): 167-201.

Cerasi V, Daltung S (2000) The optimal size of a bank: Costs and benefits of diversification. Eur. Econom. Rev. 44(9): 1701-1726.

Cho I-K, Kreps DM (1987) Signaling games and stable equilibria. Quart. J. Econom. 102(2): 179221.

Jacques C (1995) Arm's length relationships. Quart. J. Econom. 110(2): 275-295.

Drymiotes G (2007) The monitoring role of insiders. J. Accounting Econom. 44(3): 359-377.

Dutta S, Fan Q (2012) Incentives for innovation and centralized versus delegated capital budgeting. J. Accounting Econom. 53(3): 592-611.

Financial Crisis Inquiry Commission, 2011, Final report of the national commission on the causes of the financial and economic crisis in the United States.

Hermalin BE, Weisbach MS (2012) Information disclosure and corporate governance. J. Finance 67(1): 195-233.

Holmström B, Tirole J (1997) Financial intermediation, loanable funds, and the real sector. Quart. J. Econom. 112(3): $663-691$. 
THE ADVERSE EFFECT OF INFORMATION ON GOVERNANCE AND LEVERAGE

Laux C (2001) Limited liability and incentive contracting with multiple projects. RAND J. Econom. $32(3): 514-526$.

Leuz C, Triantis A, Yue Wang T (2008) Why do firms go dark? Causes and economic consequences of voluntary SEC deregistrations. J. Accounting Econom. 45(2-3): 181-208.

Li Xi (2014) The Sarbanes-Oxley act and cross-listed foreign private issuers. J. Accounting Econom. 58(1): 21-40.

Ortiz-Molina H (2007) Executive compensation and capital structure: The effects of convertible and straight debt on CEO pay. J. Accounting Econom. 43(1): 69-93.

Pae S, Seung-Weon Y (2001) Strategic interaction in auditing: An analysis of auditors' legal liability, internal control systen quality, and audit effort. Accounting Rev. 76(3): 333-356.

Pagano M, Paolo V (2012) Securitization, disclosure, and liquidity. Rev. Financial Stud. 25(8): $2417-2453$.

Permanent Subcommittee on Investigations, 2011, Wall Street and the financial crisis: Anatomy of a financial collapse, Majority and minority staff report, Washington, DC.

Ramanan RNV (2014) Corporate governance, auditing, and reporting distortions. J. Accounting, Auditing and Finance 29(3): 306-339.

Romano R (2005) The Sarbanes-Oxley Act and the making of quack corporate governance. Yale Law J. 114(7): 1521-1611.

Rotemberg JJ, Saloner G (1994) Benefits of narrow business strategies, Amer. Econom. Rev. 84(5): $1330-1349$.

SEC, 2009, Study of the sarbanes-oxley act of 2002 section 404 internal control over financial reporting requirements, Office of economic analysis report, September, Securities and Exchange Commission.

Tirole J (2006) The Theory of Corporate Finance (Princeton University Press: Princeton, NJ). 
THE ADVERSE EFFECT OF INFORMATION ON GOVERNANCE AND LEVERAGE

\section{APPENDIX}

\section{Proof of Proposition 1}

We prove Proposition 1 by identifying every equilibrium of the signaling game studied in Section 3.2. To do so, it is convenient to establish our notation.

\section{Definition 2.}

1. $\zeta$ is the probability that bondholders assign to the event that the manager shirks:

$$
\zeta=b(1-q)
$$

2. Given bondholders' assessment $\zeta$,

$$
\sigma(\zeta)=\Pi-\zeta \Delta
$$

is the bondholders' assessment of the project's success probability.

Given the assessment $\zeta$ and debt level $D$, the shareholder value from a non-manipulable project is

$$
I_{n}=\Pi\left(R_{\tau}-\frac{D}{\sigma(\zeta)}\right)-(1-D)+D \Pi \tau \frac{1-\sigma(\zeta)}{\sigma(\zeta)}
$$

the shareholder value from a manipulable project if the headquarters does not prevent shirking is

$$
I_{m}^{s}=(\Pi-\Delta)\left(R_{\tau}-\frac{D}{\sigma(\zeta)}\right)-(1-D)+\tau D(\Pi-\Delta) \frac{1-\sigma(\zeta)}{\sigma(\zeta)}
$$

and the value from a manipulable project if the headquarters does prevent shirking is

$$
I_{m}^{n s}=\Pi\left(R_{\tau}-\frac{D}{\sigma(\zeta)}\right)-(1-D)+\tau D \Pi \frac{1-\sigma(\zeta)}{\sigma(\zeta)}-k
$$

The headquarters' optimal strategy $q^{*}$ depends on the debt level $D$ and the bondholders' assessment $\zeta$ of the probability of shirking as follows.

When there is no information system, bondholders assess shirking probability $\zeta$ of 0 when $D \leq \bar{D}_{0}$, and $\mu$ otherwise. This relation is straightforward, and we therefore did not need to define $\zeta$ when considering the case without an information system. In contrast, in the signaling game with an information system, $\zeta$ could assume a range of values, and the headquarters' incentives depend 
critically upon $\zeta$. Hence, in this Appendix, we start by examining the dependence upon $\zeta$ of the headquarters' decision to make a governance intervention with an information system:

Lemma 5. The headquarters sets $q^{*}=1$ for manipulable projects, and so prevents shirking, if Condition (26) is satisfied:

$$
D<\bar{D}_{1}(\zeta)=\frac{\sigma(\zeta)\left(R_{\tau}-k / \Delta\right)}{1-\tau(1-\sigma(\zeta))}
$$

If $D>\bar{D}_{1}(\zeta)$, then the headquarters sets $q^{*}=0$ and so does not prevent shirking. If $D=\bar{D}_{1}(\zeta)$, then the headquarters is indifferent between q-values between 0 and 1.

Proof. The headquarters sets $q^{*}=1$ and prevents shirking if and only if the corresponding value $I_{m}^{n s}$ exceeds the value $I_{m}^{s}$ when it sets $q^{*}=0$ and so does not prevent shirking. This requirement is equivalent to Condition (26). The remainder of the result follows similarly.

It is easy to show that $\frac{\partial \bar{D}_{1}(\zeta)}{\partial \zeta}<0$.

The complexity in the signaling game arises because $\zeta$ depends upon $D$. To understand this dependency, it is convenient to examine the headquarters indifference curves in $(D, \zeta)$ space.

\section{Lemma 6.}

1. A manipulable firm has upward-sloping and concave indifference curves in $(D, \zeta)$ space for $D>\bar{D}_{1}(\zeta)$; for $D<\bar{D}_{1}(\zeta)$ they are upward-sloping and concave for

$$
\zeta<\zeta^{+} \equiv \frac{\Pi(1-\Pi) \tau}{\Delta(1-\tau \Pi)}
$$

and they are downward-sloping and convex for $\zeta>\zeta^{+}$;

2. A non-manipulable firm has upward-sloping and concave indifference curves for $\zeta<\zeta^{+}$, and downward-sloping and convex indifference curves for $\zeta>\zeta^{+}$;

3. Indifference curves for both types of firm are continuous.

Proof. Indifference curves for a non-manipulable firm have the form $I_{n}=C$. By Lemma 5, the indifference curves for a manipulable firm have the form $I_{m}^{n s}=C$ when $D \leq \bar{D}_{1}(\zeta)$, and $I_{m}^{s}=C$ otherwise. Mechanical differentiation of these results yields Lemma 6.

The indifference curves derived in Lemma 6 are illustrated in Figure 4. Manipulable firms prevent shirking only when $(D, \zeta)$ lies on or to the left of the line $\bar{D}_{1}(\zeta)$ : this is the reason that 


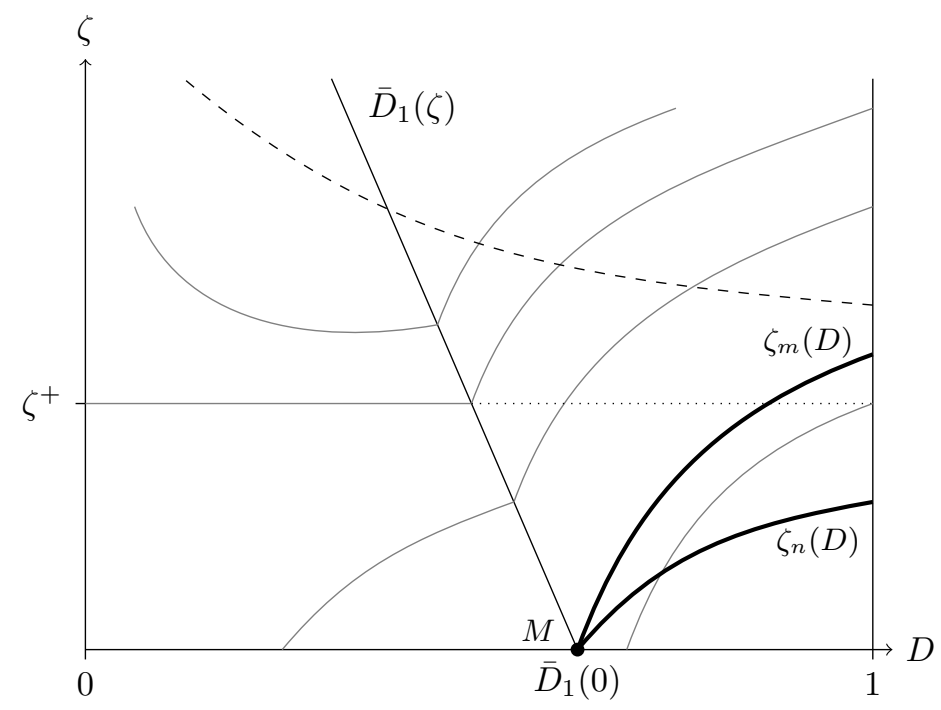

Figure 4. Headquarters indifference curves. The line $\bar{D}_{1}(\zeta)$ along which the headquarters with a manipulable project is indifferent between preventing shirking and not doing so slopes down.

the indifference curves for manipulable firms change along this line. To the right of $\bar{D}_{1}(\zeta)$, the indifference curves for manipulable firms are steeper than those for non-manipulable firms. The reason is that manipulable firms are less sensitive to interest rate changes than non-manipulable firms, because manipulable firms repay their debt with lower probability. Hence, because they experience the bondhholders' assessment $\zeta$ that they shirk via a higher interest rate, manipulable firms incur a lower cost than non-manipulable firms from an increase in $\zeta$.

Note that the tax benefit of debt increases in $D$ and also in the probability $\zeta$ that bondholders assign to shirking. Hence, the headquarters prefers indifference curves to the right and bottom of Figure 4. The following result follows immediately.

Lemma 7. The only possible equilibrium with $D \leq \bar{D}_{1}(\zeta)$ is at point $M$ on Figure 4, where $\zeta=0$ and $D=\bar{D}_{1}=\bar{D}_{1}(0)$.

Proof. Note from Lemma 5 that, if the headquarters sets $D=\bar{D}_{1}$, then there will never be shirking on manipulable projects, so that $\zeta=0$. Hence, the headquarters can always elect to situate itself at the point $\left(D=\bar{D}_{1}, \zeta=0\right)$ on Figure 4 . This point is preferred to every other point to the left of $\bar{D}_{1}(\zeta)$ and, hence, it is the only possible equilibrium with $D \leq \bar{D}_{1}$.

We write $\zeta_{n}(D)$ and $\zeta_{m}(D)$ for the respective indifference curves through $\left(D=\bar{D}_{1}, \zeta=0\right)$ of non-manipulable and manipulable firms. These curves are indicated as thicker lines in Figure 4. 
THE ADVERSE EFFECT OF INFORMATION ON GOVERNANCE AND LEVERAGE

Lemma 8. There exist no separating equilibria.

Proof. The full proof of this result appears in the Online Appendix. In outline, in any candidate separating equilibrium manipulable projects cannot have a higher debt level than $\bar{D}_{1}(\zeta)$, since they would otherwise have negative value and so fail to attract funding. Non-manipulable firms therefore have higher debt levels. Since both projects have equilibrium assessment $\zeta=0$, manipulable firms choose to imitate the higher debt levels of non-manipulable firms, which violates the separating assumption. We also show in the Online Appendix that there are no separating equilibria where the non-manipulable firm leaves money on the table to signal a high success probability.

Throughout the paper, we assume that the bondholders' participation constraint is binding. The proof of Lemma 8 demonstrates that this is indeed optimal.

Lemma 9. There exists a pooling equilibrium with $D=\bar{D}_{1}$. That pooling equilibrium is the unique equilibrium in which shirking is prevented.

The proof of Lemma 9 appears in the Online Appendix. It shows that the pooling equilibrium is sustained by a posterior bondholder belief $\zeta=1$ for any $D>\bar{D}_{1}$.

We now establish the conditions under which a pooling equilibrium could exist for $D>\bar{D}_{1}$ in which shirking is not prevented. In any such equilibrium we must have $\zeta=\mu$, and, to ensure that non-manipulable firms do not defect to point $M$, the equilibrium must be at a point below $\zeta_{n}(D)$ in $(D, \zeta)$ space; this is possible whenever $\mu$ lies below

$$
\bar{\mu}_{1} \equiv \zeta_{n}(1)
$$

as illustrated in Figure 5. Then there is a pooling equilibrium at any point $\left(D^{\prime}, \mu\right)$ along the horizontal dashed line from $\zeta_{n}(D)$ to $(1, \mu)$, which is sustained by the bondholder belief that $\zeta=1$ for every $D>D^{\prime}$. We have therefore established Lemma 10:

Lemma 10. There exist pooling equilibria with debt levels above $\bar{D}_{1}$ if and only if $\mu<\bar{\mu}_{1}$. When $\mu<\bar{\mu}_{1}$, let $D_{\mu}=\zeta_{n}^{-1}(\mu)$; there is a continuum of pooling equilibria for every $D \in\left[D_{\mu}, 1\right]$.

We now consider possible mixed equilibria. Lemma 11 establishes that there cannot be an equilibrium in which a manipulable firm adopts a mixed strategy. We prove this result in the Online Appendix; the intuitive reason for the result is that in such an equilibrium at least one of 


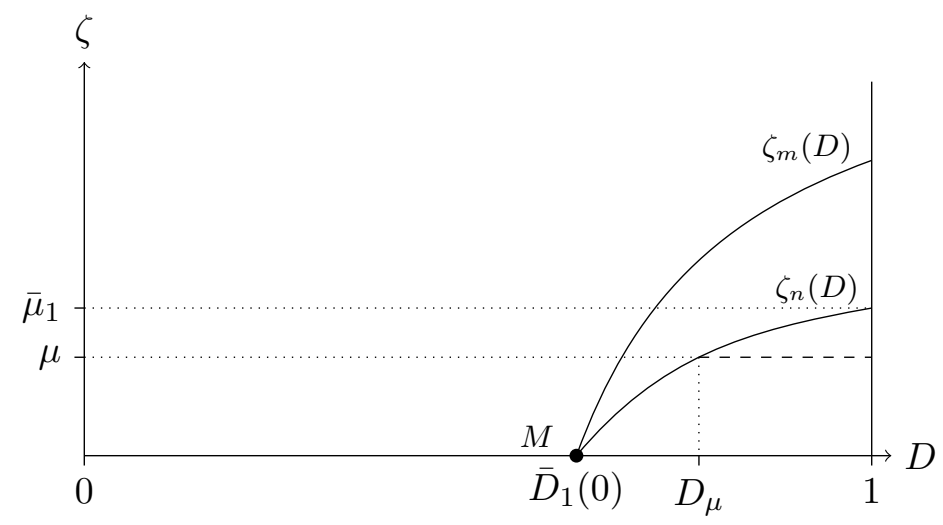

Figure 5. Pooling equilibria with $D>\bar{D}_{1}$. In any pooling equilibrium with $D>\bar{D}_{1}(0)$, the assessment $\zeta$ must equal the population proportion $\mu$ of manipulable projects. Non-manipulable firms will not deviate to $M$ only if the pooling equilibrium lies below $\zeta_{n}(\cdot)$; hence, pooling equilibria exist only if $\mu<\bar{\mu}_{1}=\zeta_{n}(1)$. They can then be sustained anywhere along the dashed line.

the manipulable firm's possible actions would reveal its type, and so ensure that it could not be individually rational.

Lemma 11. There is no equilibrium in which a manipulable firm adopts a mixed strategy.

Lemma 11 implies that, if there is a partially separating equilibrium, it must involve mixing by non-manipulable firms. Lemma 12, which is proved in the Online Appendix, establishes the properties of those equilibria.

Lemma 12. There exist partially separating equilibria in which non-manipulable firms mix if and only if $\mu<\bar{\mu}_{1}$. In that case, there is a partially separating equilibrium for any $\tilde{D}>\bar{D}_{1}$ for which the indifference curve through $(\tilde{D}, 0)$ intersects the $\zeta$-axis above $\mu$. Given such a $\tilde{D}$, let $D_{\mu}^{*}$ be the capital structure at which the non-manipulable firm's indifference curve through $(\tilde{D}, 0)$ intersects the line $\zeta=\mu$. Then there is a continuum of mixed strategy equilibria for each $\hat{D} \in\left[0, D_{\mu}^{*}\right]$; in every such equilibrium, manipulable firms set $D=\hat{D}$ and non-manipulable firms mix between $\tilde{D}$ and $\hat{D}$.

Lemmas 9, 10 and 12 together imply Proposition 1:

Corollary 2 (Proposition 1). If $\mu \geq \bar{\mu}_{1}$ then the only equilibrium of the signaling game is the pooling equilibrium of Lemma 9. If $\mu<\bar{\mu}_{1}$ then there is a continuum of pooling equilibria with $D>$ $\bar{D}_{1}$, described in Lemma 10, and a continuum of partially separating equilibria in which manipulable firms select a $D>\bar{D}_{1}$, described in Lemma 12. 
THE ADVERSE EFFECT OF INFORMATION ON GOVERNANCE AND LEVERAGE

\section{Proof of Lemma 3}

A complete proof of this result appears in the Online Appendix. The proof identifies the functional form of the non-manipulable firm's indifference curve $I_{n}$ and so derives the threshold $\bar{\mu}_{1}$ by considering the curve through $(\zeta=0, D=\bar{D})$. The comparative statics are obtained by direct differentiation.

\section{Proof of Lemma 4}

The complete proof of this result appears in the Online Appendix. It proceeds as follows: (1) When $\mu<\bar{\mu}_{1}$, Shirking Equilibria generate higher shareholder value than the Incentive Equilibrium; (2) It follows that the headquarters never implements an information system when $\mu \leq \bar{\mu}_{1} ;(3) \bar{\mu}_{1} \geq \bar{\mu}_{0}$, so that the headquarters never performs governance interventions when $\mu \leq \bar{\mu}_{1}$.

\section{Proof of Proposition 3}

The full proof of this result appears in the Online Appendix. Our proof starts from the bondholders' belief that the firm has an information system for debt levels $D \leq \bar{D}_{1}^{u}$. We then obtain the debt level $\bar{D}_{1}^{u}$ of Equation (21) by equating the shareholder value achieved by setting $D=\bar{D}_{1}^{u}$ and deploying an information system to the value achieved by setting $D=\bar{D}_{1}^{u}$ and not doing so. The headquarters' implementation decision is similarly obtained by identifying the highest value choices for possible $\mu$ values. 


\section{ON-LINE APPENDIX}

\section{Proof of Lemma 3}

$\bar{\mu}_{1}=\zeta_{n}(1)$, where $\zeta_{n}(D)$ is the non-manipulable firm indifference curve through $D_{1}(0)$. So the relevant indifference curve has the form $I_{n}(\zeta, D)=C$, which can be written in the following way when $D=1$ :

$$
\bar{\mu}_{1}=\frac{\Pi\left(C-\Pi R_{\tau}+\Pi \tau+1-\tau\right)}{\Delta\left(C-\Pi R_{\tau}+\Pi \tau\right)} .
$$

We have

$$
\begin{aligned}
C & =I_{n}(\zeta=0 ; D=\bar{D}) \\
& =\Pi R_{\tau}-1+\bar{D}_{1}(1-\Pi) .
\end{aligned}
$$

It follows by direct substitution that

$$
\bar{\mu}_{1}=\frac{\tau \Pi(1-\Pi)\left(1-\bar{D}_{1}\right)}{\Delta\left(1-\Pi \tau-\bar{D}_{1} \tau(1-\Pi)\right)} .
$$

Direct differentiation yields

$$
\begin{aligned}
\frac{\partial \bar{\mu}_{1}}{\partial \bar{D}_{1}} & =-\frac{\tau \Pi(1-\Pi)(1-\tau)}{\Delta\left(1-\Pi \tau-\bar{D}_{1} \tau(1-\Pi)\right)^{2}}<0 ; \\
\frac{\partial \bar{D}_{1}}{\partial \tau} & =-\Pi \frac{(\Pi R-1)+k(1-\Pi) / \Delta}{(1-\tau(1-\Pi))^{2}}<0 \\
\left.\frac{\partial \bar{\mu}_{1}}{\partial \tau}\right|_{\bar{D}_{1} \text { fixed }} & =\frac{\Pi(1-\Pi)\left(1-\bar{D}_{1}\right)}{\Delta\left(1-\Pi \tau-\bar{D}_{1} \tau(1-\Pi)\right)^{2}}>0
\end{aligned}
$$

We then have

$$
\begin{aligned}
\frac{\partial \bar{\mu}_{1}}{\partial R} & =\frac{\partial \bar{\mu}_{1}}{\partial \bar{D}_{1}}(1-\tau) \frac{\partial \bar{D}_{1}}{\partial R_{\tau}}<0 ; \\
\frac{\partial \bar{\mu}_{1}}{\partial k} & =-\frac{\partial \bar{\mu}_{1}}{\partial \bar{D}_{1}} \frac{\Pi}{\Delta(1-\tau(1-\Pi))}>0 ; \\
\frac{\partial \bar{\mu}_{1}}{\partial \Delta} & =-\frac{\bar{\mu}_{1}}{\Delta}+\frac{\partial \bar{\mu}_{1}}{\partial \bar{D}_{1}} \frac{k \Pi}{\Delta^{2}(1-\tau(1-\Pi))}<0 \\
\frac{\partial \bar{\mu}_{1}}{\partial \tau} & =\frac{\partial \bar{\mu}_{1}}{\partial \bar{D}_{1}} \frac{\partial \bar{D}_{1}}{\partial \tau}+\left.\frac{\partial \bar{\mu}_{1}}{\partial \tau}\right|_{\bar{D}_{1} \text { fixed }}>0 .
\end{aligned}
$$




\section{Proof of Lemma 4}

First, note that, when $\mu<\bar{\mu}_{1}$, so that Shirking Equilibria are possible with an information system, Shirking Equilibria generate higher expected headquarters surplus than the Incentive Equilibria. This result is immediate by inspection of Figure 5, because Shirking Equilibria lie on the thick dashed line, which intersects indifference curves below the ones through $M$.

It follows that the headquarters strictly prefers not to implement an information system when $\mu \leq \bar{\mu}_{1}$. To show that it never makes a governance intervention we must therefore demonstrate that $\bar{\mu}_{1} \leq \bar{\mu}_{0}$.

Shirking Equilibria are possible with an information system precisely when $\mu \leq \bar{\mu}_{1}$ : when this condition is satisfied, Shirking Equilibria can occur for a continuum of $D$ when the non-manipulable firm indifference curve through $\bar{D}_{1}$ crosses the line $D=1$ above $\zeta=\mu$ (see Figure 5 ). In other words, there are Shirking Equilibria (which co-exist with the Incentive Equilibrium) when the following condition is satisfied:

$$
I_{n}(D=1, \zeta=\mu)>I_{n}\left(D=\bar{D}_{1}, \zeta=0\right) .
$$

This requirement reduces to the following condition:

$$
\tau(1-\Pi) D_{0} \leq(1-\Pi) \tau+(1-\tau)\left(1-\frac{\Pi}{\Pi-\mu \Delta}\right)-\tau(1-\Pi) \frac{\Pi(1-\mu)}{1-\tau(1-\Pi} \frac{k}{\mu \Delta} .
$$

The condition for non-shirking without an information system is Equation (14), which we can write as follows:

$$
\tau(1-\Pi) D_{0} \geq \tau(1-\pi)-\left(\mu \Delta R_{\tau}-k\right)
$$

Conditions (27) and (28) can be satisfied simultaneously, so that $\bar{\mu}_{0}<\bar{\mu}_{1}$, precisely when Condition (29) holds:

$$
(1-\tau)\left(1-\frac{\Pi}{\Pi-\mu \Delta}\right)-\tau(1-\Pi) \frac{\Pi(1-\mu)}{1-\tau(1-\Pi} \frac{k}{\mu \Delta} \geq \mu \Delta \tau-\left(\mu \Delta R_{\tau}-k\right) .
$$

Because $\bar{D}_{0}<1$ we have

$$
\mu \Delta \tau-\left(\mu \Delta R_{\tau}-k\right)>-(1-\tau) \frac{\mu \Delta}{\Pi}
$$


THE ADVERSE EFFECT OF INFORMATION ON GOVERNANCE AND LEVERAGE

and, because the right-hand side of this expression exceeds $(1-\tau)(1-\Pi /(\Pi-\mu \Delta))=-(1-$ $\tau) \mu \Delta /(\Pi-\mu \Delta)$, Condition (29) cannot be satisfied.

\section{Proof of Lemma 8}

The proof proceeds in two steps. We first consider the case where the participation constraint of bondholders is binding, which we assume throughout the paper. Let $D_{n}$ and $D_{m} \neq D_{n}$ be the respective debt levels of non-manipulable and manipulable projects in a separating equilibrium. We must have $D_{m} \leq \bar{D}_{1}(\zeta)$, since otherwise manipulable projects, whose type is revealed in equilibrium, have negative value and, hence, do not attract funding. Hence, by Lemma $7, D_{m}=\bar{D}_{1}<D_{n}$, and the equilibrium assessment $\zeta$ must be zero for both types of project. But, for fixed $\zeta$, shareholder value is increasing in the debt level $D$. Hence, a headquarters with a manipulable project will choose to imitate one with a non-manipulable project, thus violating the separating assumption.

We now show that there exists no separating equilibrium where the non-manipulable firm leaves money on the table to signal a high probability of success. Assume, on the contrary, that the non-manipulable firm sets $D=1$ and $B>\frac{1}{\Pi}$ (with bondholders' assessment $\zeta=0$ ) and that the manipulable firm chooses $D=\bar{D}_{1}$, so that shirking does not occur: bondholders assess $\zeta=0$ and bonds are fairly priced at $\bar{D}_{1} / \Pi$. $B$ must satisfy the self-selection constraint of the manipulable firm, who must elect not to set $D=1$ instead of $D=\bar{D}_{1}$. This requirement reduces to

$$
(\Pi-\Delta)\left(R_{\tau}-B\right)+\tau(\Pi-\Delta)(B-1) \leq \Pi R_{\tau}-1+\tau \bar{D}_{1}(1-\Pi)-k .
$$

The non-deviation criterion for a non-manipulable firm is

$$
\Pi\left(R_{\tau}-B\right)+\tau \Pi(B-1) \geq \Pi R_{\tau}-1+\tau \bar{D}_{1}(1-\Pi) .
$$

Conditions (30) and (31) can be satisfied simultaneously whenever

$$
(\Pi-\Delta)\left(R_{\tau}-B\right)+\tau(\Pi-\Delta)(B-1)+k \leq \Pi\left(R_{\tau}-B\right)+\tau \Pi(B-1),
$$

which reduces to

$$
k \leq \Delta\left(R_{\tau}-B\right)+\Delta \tau(B-1) .
$$


Recall from Equation (16) that $\bar{D}_{1}(1-\tau(1-\Pi))=\Pi\left(R_{\tau}-k / \Delta\right)$. We can therefore write Condition (32) as follows:

$$
\frac{\Pi B(1-\tau)+\tau \Pi}{1-(1-\Pi) \tau} \leq \bar{D}_{1}
$$

But for $B>1 / \Pi$ we have

$$
\frac{\Pi B(1-\tau)+\tau \Pi}{1-(1-\Pi) \tau}>\frac{1-\tau+\tau \Pi}{1-\tau+\tau \Pi}=1>\bar{D}_{1},
$$

which contradicts Condition (33), so that the candidate equilibrium cannot exist.

\section{Proof of Lemma 9}

The pooling equilibrium is sustained by a posterior bondholder belief $\zeta=1$ for any $D>\bar{D}_{1}$. This belief ensures that any deviation by a manipulable firm renders its bonds fairly priced so that, by Equation (4), its participation constraint is violated.

A non-manipulable firm also does not deviate since the increase in shareholder value is then negative: If it deviates, it is optimal to choose $D=1$, which, by Equation (4), yields a negative shareholder value for bondholder belief $\zeta=1$ so that the firm cannot finance itself.

We must also demonstrate that the pooling equilibrium is robust to the Intuitive Criterion. This is true because any type could benefit from deviation under the belief $\zeta(D)=0$, so that the Intuitive Criterion places no restriction upon off-equilibrium beliefs in this case.

Finally, we demonstrate uniqueness. By Lemma 8, any equilibrium in which shirking is prevented must be a pooling equilibrium, with $D \leq \bar{D}_{1}$. And by Lemma 7 , there is no equilibrium with $D<\bar{D}_{1}$

\section{Proof of Lemma 11}

Suppose for a contradiction that such an equilibrium exists. The manipulable firm must mix amongst points on a single indifference curve. Let $x$ and $y$ be points on the curve that the manipulable firm selects with positive probability, as in Figure 6. The non-manipulable firm strictly prefers $y$ because, as illustrated, it lies on a lower indifference curve. Hence, a debt level choice $D_{x}$ reveals the project to be manipulable, so that $\zeta_{x}=1$. The indifference curve along which manipulable firms mix therefore violates the manipulable firms' participation constraint. 


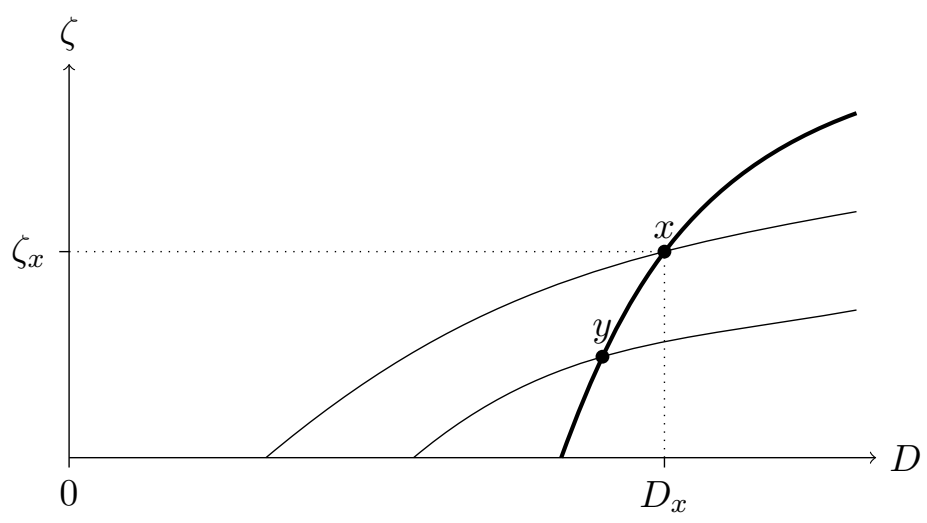

Figure 6. Non-existence of equilibria in which manipulable firms mix. If manipulable firms mixed between $x$ and $y$ then both points would have to lie on a common manipulable firm indifference curve, illustrated as a thick line in the Figure. The lower point would be strictly preferred by a non-manipulable firm, so that choosing debt $D_{x}$ would reveal a firm to be manipulable and, hence, because $D_{x}>\bar{D}_{1}$, would imply that $x$ violated the participation constraint.

\section{Proof of Lemma 12}

If there is a partially separating equilibrium, it must involve mixing by non-manipulable firms. Such mixing can only occur on an indifference curve below $\zeta_{n}(D)$, along which the outside option associated with the commitment point $M$ is achieved. Such an indifference curve is illustrated as a bold curve in Figure 7. If a non-manipulable firm mixes between at least two points on this curve, then the manipulable firm will select the rightmost point, since this point lies on the most attractive manipulable firm indifference curve. All other points must therefore have $\zeta=0$ and, hence, the non-manipulable firm can mix between only two points, illustrated in Figure 7 with capital levels $\hat{D}$ and $\tilde{D}$. The market belief $\hat{\zeta}$ when $D=\hat{D}$ at the right-hand point must lie above $\mu$ (because all manipulable and not all non-manipulable firms select this debt level) and below $\bar{\mu}_{1}$ (since the bold indifference curve must lie below the outside option $\left.\zeta_{n}(\cdot)\right)$. Hence, partially separating equilibria are feasible only if $\mu<\bar{\mu}_{1}$. If this condition holds, then a partially separating equilibrium can be sustained along any indifference curve below $\zeta_{n}(\cdot)$ with $\tilde{D}$ and $\hat{D}>D_{\mu}^{*}$ as illustrated, with off-equilibrium beliefs $\zeta=1$.

\section{Proof of Proposition 3}

When information systems are not observable, suppose that bondholders believe that when $D \leq \bar{D}_{1}^{u}$, the firm prefers to implement an information system rather than not to do so, and not to perform a governance intervention. With this belief, the firm's debt repayment if it sets $D \leq \bar{D}_{1}^{u}$ is $D / \Pi$. 


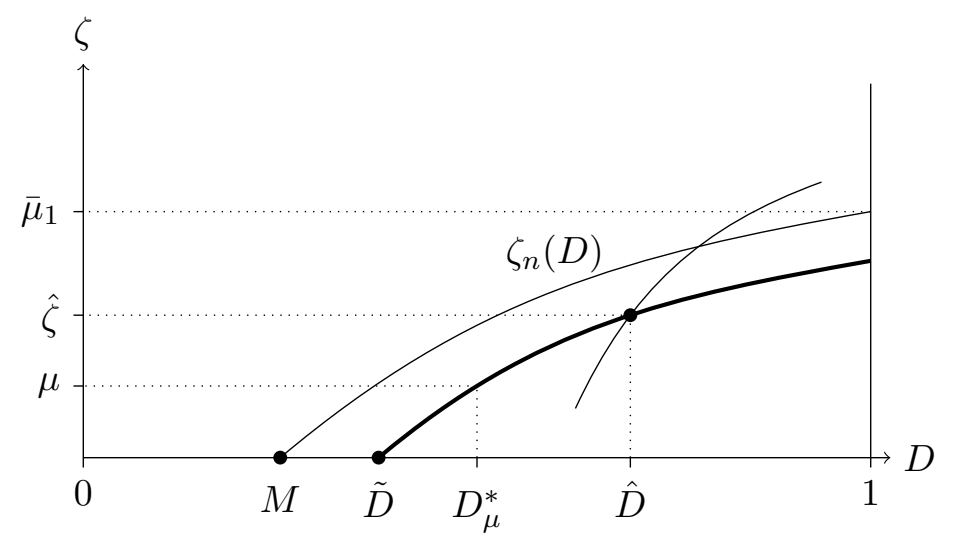

Figure 7. Partially separating equilibria. Equilibria in which non-manipulable firms mix exist if and only if there is a non-manipulable firm indifference curve below $\zeta_{n}(\cdot)$ that intersects the $\zeta$-axis above $\mu$, as illustrated by the bold line in the Figure. In such equilibria non-manipulable firms mix between the $D$-axis intercept $\tilde{D}$ and any $\hat{D}>\tilde{D}$; manipulable firms always set $D=\hat{D}$.

It follows that the headquarters derives the following shareholder value from assuming debt level $D \leq \bar{D}_{1}^{u}$ and implementing an information system:

$$
V_{1}^{u, n s} \equiv \Pi R_{\tau}-1-(1-\Pi \tau) \delta-\mu k+\tau(1-\Pi) D
$$

The firm's value if it sets $D=\bar{D}_{1}^{u}$ in order to benefit from cheap debt and nevertheless shirks is $V^{\text {dev }}$, which is obtained by replacing $p(q)$ with $\pi$ and setting $B=\bar{D}_{1}^{u} / \Pi$ in Equation (6):

$$
V^{\text {dev }}=\pi R_{\tau}-1+\bar{D}_{1}^{u}\left(1-\frac{\pi}{\Pi}\right)+\frac{\pi}{\Pi} \bar{D}_{1}^{u} \tau(1-\Pi)
$$

We have

$$
V^{d e v}-V_{1}^{u, n s}=-(\Pi-\pi) R_{\tau}+(1-\Pi \tau) \delta+\mu k+\bar{D}_{1}^{u} \frac{\Pi-\pi}{\Pi}(1-\tau(1-\Pi)) .
$$

The bondholders' belief is sustainable in equilibrium precisely when $V^{\text {dev }}-V_{1}^{u, n s} \leq 0$; this is true for $D$ less than or equal to the debt level $\bar{D}_{1}^{u}$ of Equation (21).

Given this belief set, the headquarters chooses between (i) implementing an information system, setting $D=\bar{D}_{1}^{u}$, and performing a governance intervention when the project is manipulable; (ii) not implementing an information system, setting $D=\bar{D}_{0}$, and performing a governance intervention; and (iii) setting $D=1$, not implementing an information system, and not performing a governance 
intervention. Option (i) dominates option (iii) if and only if

$$
\begin{aligned}
V_{1}^{u, n s}-V_{0}^{s}=\mu \Delta R_{\tau}-k & -\tau\left((1-\pi)-(1-\Pi) \bar{D}_{0}\right) \\
+ & \left(\frac{1+\tau(1-\Pi)(\Pi /(\Pi-\pi)-1)}{1-\tau(1-\Pi)}\right)(k(1-\mu)-(1-\Pi \tau) \delta) \geq 0 .
\end{aligned}
$$

Option (ii) dominates option (iii) if and only if Condition (14) is satisfied. Hence, shirking is prevented precisely when Condition (38) is satisfied:

$$
\begin{aligned}
\mu \Delta R_{\tau}-k \geq \tau((1-\pi)- & \left.(1-\Pi) \bar{D}_{0}\right)- \\
& \left(\frac{1+\tau(1-\Pi)(\Pi /(\Pi-\pi)-1)}{1-\tau(1-\Pi)}\right) \max (k(1-\mu)-(1-\Pi \tau) \delta, 0) .
\end{aligned}
$$

$\bar{\mu}^{u}$ is the value of $\mu$ at which Condition (38) is satisfied with equality, so that Condition (38) is equivalent to the requirement that $\mu>\bar{\mu}^{u}$.

Finally, option (i) dominates option (ii) when

$$
V_{1}^{u, n s}-V_{0}^{n s}=\left[\frac{\Pi-\pi+\pi \tau(1-\Pi)}{(\Pi-\pi)(1-\tau(1-\Pi))}\right](k(1-\mu)-(1-\Pi \tau) \delta) \geq 0 .
$$

This condition is equivalent to the statement that $\mu<\mu_{1}^{\max , u}$.

In short, we have:

1. $\mu \leq \bar{\mu}^{u}$ : option (iii) is dominant: the headquarters sets $D=1$, does not implement an information system, and never makes a governance intervention;

2. $\bar{\mu}^{u}<\mu \leq \mu_{1}^{\max , u}$ : option (i) is dominant: the headquarters sets $D=\bar{D}_{1}^{u}$, implements an information system, and performs a governance intervention if the project is manipulable;

3. $\mu>\mu_{1}^{\max , u}$ : option (ii) is dominant: the headquarters sets $D=\bar{D}_{0}$ and always performs a governance intervention. 